\title{
Quantum-chemical study of luminescence efficiency and excited state structures of some mesogenic europium(III) complexes with $\beta$ diketones and Lewis bases
}

\author{
Ksenia Romanova $^{1}$ and Yuriy G. Galyametdinov ${ }^{1}$ \\ ${ }^{1}$ Kazan National Research Technological University
}

January 20, 2022

\begin{abstract}
Metal-containing liquid crystals and, in particular, $\operatorname{Ln}(\mathrm{III})$ complexes with unique structural, liquid-crystalline (LC), optical and magnetic properties are the examples of currently relevant multifunctional materials. Indirect structure-property relationships, their dependence on various factors and insufficiently studied determinant physicochemical mechanisms complicate the application of mesogenic $\operatorname{Ln}(\mathrm{III})$ complexes. While $\operatorname{Ln}(\mathrm{III})$ and ligand environment are selected prior to the synthesis, structural features of coordination polyhedra, especially upon photoexcitation, are not uniquely defined. Therefore, this work is focused on the development of theoretical approaches to the creation of multifunctional materials based on highly luminescent mesogenic $\mathrm{Eu}(\mathrm{III})$ complexes with $\beta$ diketones and Lewis bases. The relationships between their structure, parameters of Voronoi-Dirichlet polyhedra, luminescence efficiency and LC properties were considered. The calculated excited states and intramolecular energy transfer rates were used to determine intramolecular energy transfer channels. It was shown that their LC behavior is mainly defined by the ligand environment, while optical properties can also be determined by the coordination polyhedra.
\end{abstract}

Quantum-chemical study of luminescence efficiency and excited state structures of some mesogenic europium(III) complexes with $\beta$ diketones and Lewis bases

Ksenia Romanova, Yuriy Galyametdinov

Physical and Colloid Chemistry Department, Kazan National Research Technological University, Karl Marx Street 68, Kazan 420015, Russia.

\section{Correspondence}

Ksenia Romanova, Department of Physical and Colloid Chemistry, Kazan National Research Technological University, Karl Marx Street 68, Kazan 420015, Russia. Email: ksenuya@mail.ru

Metal-containing liquid crystals and, in particular, $\operatorname{Ln}(\mathrm{III})$ complexes with unique structural, liquidcrystalline (LC), optical and magnetic properties are the examples of currently relevant multifunctional materials. Indirect structure-property relationships, their dependence on various factors and insufficiently studied determinant physicochemical mechanisms complicate the application of mesogenic Ln(III) complexes. While $\operatorname{Ln}(\mathrm{III})$ and ligand environment are selected prior to the synthesis, structural features of coordination polyhedra, especially upon photoexcitation, are not uniquely defined. Therefore, this work is focused on the development of theoretical approaches to the creation of multifunctional materials based on highly luminescent mesogenic Eu(III) complexes with $\beta$ diketones and Lewis bases. The relationships between their structure, parameters of Voronoi-Dirichlet polyhedra, luminescence efficiency and LC properties were considered. The calculated excited states and intramolecular energy transfer rates were used to determine 
intramolecular energy transfer channels. It was shown that their LC behavior is mainly defined by the ligand environment, while optical properties can also be determined by the coordination polyhedra.

Keywords - europium complexes, metallomesogens, energy transfer, coordination polyhedra, density functional theory.

\section{INTRODUCTION}

One of the most desirable findings for materials scientists are the correlations between properties of materials and their components' molecular structure according to the reliably studied relationships. Quantum-chemical simulation offers promising and reliable instruments to succeed in these tasks, especially useful in the case of lanthanide(III) $(\operatorname{Ln}(\mathrm{III}))$ based materials and their mesogenic representatives. Prospective liquid-crystalline (LC) behavior and unique physico-chemical properties determine the application of mesogenic Ln(III) complexes in optoelectronics, photonics and biomedicine, as biomarkers and contrast agents in tomography, components of solar cells, optical amplifiers and fibers, diodes, information storage and many other photonic devices. ${ }^{[1-4]}$ Distinctive $f f$ transitions in the inner $4 f$ shell of $\operatorname{Ln}(\mathrm{III})$ ion define their high luminescence intensity, narrow emission bands, significant lifetimes of excited states and Stokes shifts. ${ }^{[5,6]}$ Their emission efficiency is firstly determined by the nature of the central ion and the intramolecular energy transfer between excited states of ligands and Ln(III) ("antenna effect"). Thermostable and polymorphic mesogenic Ln(III) complexes can be also easily oriented by weak external magnetic or electric fields. ${ }^{[7-9]}$ Their magnetic properties and significant anisotropy of the magnetic susceptibility depend on the type of the coordination polyhedron and the nature of the $\operatorname{Ln}(\mathrm{III})$ ion. ${ }^{[10]}$ Europium(III) (Eu(III)) mesogenic complexes exhibit increased anisotropy of the magnetic susceptibility, large spins and strong electron correlation, effective optical properties, high emission intensity and density of excited states. ${ }^{[7-11]}$

The presence of long alkyl substituents in mesogenic $\operatorname{Ln}(\mathrm{III})$ complexes make it difficult to experimentally obtained their molecular structure and to grow a single crystal for X-ray diffraction analysis. ${ }^{[7-9,11]}$ Consequently, quantum-chemical simulation is one of the main opportunities to study this compounds and to predict structures with improved properties. Though most of the quantum-chemical studies of $\operatorname{Ln}(\mathrm{III})$ containing compounds refer to the simulation of non-LC molecules with a much simpler ligand environment than in mesogenic Ln(III) complexes. ${ }^{[12-26]}$

Semi-empirical Sparkle model was specially constricted for the simulations of the equilibrium geometry of Ln(III) complexes, their IR spectra or optical properties. ${ }^{[12,13]}$ It allows one to perform fast calculations with potentially overestimated results due to the strong dependence of the parameterization method. The study of quasi-degenerate excited states of Ln(III) complexes, complicated conical intersections can be performed with reliable multireference $a b$ initio methods. These approaches process singlet and triplet states with equal accuracy for further simulation of spin-orbit coupling, rate constants and quantum yields. ${ }^{[14-16]}$ They were effectually used for the study of the emission efficiency of binuclear $\operatorname{Ln}($ III) complexes without LC properties, ${ }^{[16]}$ energy transfer processes, ${ }^{[17]}$ luminescence mechanisms of $\operatorname{Ln}(\mathrm{III})$-doped phosphors, ${ }^{[18]}$ zero-field splitting calculations in the ground state, ${ }^{[18,19]}$ and excited states of $\operatorname{Ln}(\mathrm{III})$ complexes with much simpler ligand environment than in mesogenic compounds. ${ }^{[14,23-26]}$ Nevertheless, such qualitatively correct and accurate approaches are much more computationally expensive than semi-empirical and density functional theory (DFT) methods especially for the study of polyatomic mesogenic $\operatorname{Ln}(\mathrm{III})$ complexes. Therefore, it becomes clear why DFT with its time-dependent variant TDDFT are often used in theoretical studies of $\operatorname{Ln}(\mathrm{III})$ compounds for their aqua-complexes, ${ }^{[20,21]}$ IR spectra calculations, ${ }^{[22]}$ magnetic and optical behaviour in Ln-doping systems, ${ }^{[23]}$ study of mechanisms of intramolecular energy transfer and excited state simulations, ${ }^{[8,11,17,24-26]}$ etc. In our recent work ab initio molecular dynamics together with DFT were used to study inter- and intramolecular interactions in mesophases, the supramolecular organization and LC behavior of La(III) complexes. ${ }^{[27]}$

In this work, we studied mesogenic $\mathrm{Eu}(\mathrm{III})$ complexes that show specific LC behavior, low viscosity smectic 
and nematic mesophases in a wide temperature range in combination with unique photophysical and magnetic properties. ${ }^{[7-9,11]}$ We optimized the geometry of complexes in the ground and triplet excited states. The calculated values of geometric anisotropy allowed us to evaluate their LC behavior depending on the ligand environment. The calculated energies of the lowest triplet excited states and parameters of VDP in the optimized geometries of the excited states were used for characterization of their intramolecular energy transfer and correlation between polyhedra structure, magnetic behavior and emission efficiency.

\section{COMPUTATIONAL METHODS}

The geometry optimization of mesogenic $\mathrm{Eu}(\mathrm{III})$ complexes in the ground state was performed by the DFT method using the Priroda 06 software. ${ }^{28,29]}$ According to our previous studies ${ }^{[8,9,11,27,30]}$ we used generalized gradient approximation with the Perdew-Burke-Ernzerhof (PBE) exchange-correlation functional. ${ }^{[31]}$ Relativistic basis sets $\mathrm{rL11}$ for $\mathrm{Eu}(\mathrm{III})$ and $\mathrm{rL1}$ for other atoms within the scalar relativistic approximation were used. ${ }^{[32]}$ These sets are analogues of the cc-pVDZ and cc-pCVDZ double-zeta basis sets of Dunning, respectively. ${ }^{[33]}$ Calculations were performed for isolated molecules without symmetry constraints. Optimization ended when the gradient value reached $3[?] 10^{6} \mathrm{eV} / \AA$, the SCF convergence accuracy was set to $3[?] 10^{5} \mathrm{eV}$.

The types of coordination polyhedra were determined using the SHAPE software. ${ }^{[34-36]}$ This program uses sets of points of continuous shape which correspond to the positions of atoms in optimized geometries of molecules and determines polyhedra by the smallest deviations of these sets from the vertices of ideal reference polyhedra.

Experimental IR spectra were observed for pressed thin tablets of $\mathrm{Eu}(\mathrm{III})$ complexes with potassium bromide on ALPHA FT-IR spectrometer (Bruker) with a spectral of range $375-7500 \mathrm{~cm}^{-1}$ and resolution $4 \mathrm{~cm}^{-1}$. The vibrational modes of the IR spectra were calculated by the DFT method and PBE0 functional, as well as the NMR chemical shifts with the gauge-independent atomic orbital method. Experimental chemical shifts were taken from other publications. ${ }^{[8,9,30,37]}$

TDDFT method with various density functionals was unable to separately localize triplet excitation on each of the ligands in the studied $\mathrm{Eu}$ (III) complexes during the optimization of the excited state structures. The obtained excited states were intraligand or delocalized. Unlike density functional-based methods, configuration interaction singles method (CIS) correctly predicted excitation localization on separate ligands. Therefore, in this work the triplet excited state structures were optimized by the CIS method using the Firefly v. 8 software which is partially based on the GAMESS code. ${ }^{[38,39]}$ For $\mathrm{Eu}(\mathrm{III})$ ions the scalar quasirelativistic 4f-in-core pseudopotential ECP52MWB with the associated valence basis set was used, ${ }^{[40,41]}$ for other atoms - 6-31G(d,p). Then TDDFT/PBE0 method was applied for CIS optimized geometries to calculate the values of triplet excited states. Empirical dispersion correction (DFT-D version 4 with Becke-Johnson damping) ${ }^{[42]}$ was used to improve the long-range behavior of DFT.

To determine the experimental values of the triplet excited states, we used the phosphorescence spectra of gadolinium(III) (Gd(III)) complexes with the corresponding ligands which are characterized by a clear phosphorescence band of ligands. ${ }^{[8,43,44]}$

In order to evaluate the emission efficiency of the studied $\mathrm{Eu}(\mathrm{III})$ complexes, the intramolecular energy transfer rates from the triplet levels of ligands to the resonance levels of $\mathrm{Eu}(\mathrm{III})$ were calculated according to the procedure described in $[45,46]$. The theoretical values of quantum yields were compared to the previously obtained experimental absolute quantum yields. ${ }^{[47]}$

The structure-topological software package ToposPro V. 5.3.3.4 was used for the analysis of Voronoi-Dirichlet polyhedra (VDP) after optimization of the ground and excited state structures. ${ }^{[48]}$ 


\section{RESULTS AND DISCUSSION}

\subsection{Optimized geometries of the ground state}

$\mathrm{Eu}(\mathrm{III})$ complexes with $\beta$-diketones were chosen among other $\mathrm{Ln}(\mathrm{III})$ coordination compounds for their intensive emission properties due to the high molar absorption coefficients of ligands and suitable positions of the excited levels of $\mathrm{Eu}(\mathrm{III})$ and ligands. ${ }^{[1-6]}$ Ligand environment of $\mathrm{Ln}(\mathrm{III})$ complexes specifies their LC behavior and emission properties. In this work we selected objects with various substituted $\beta$-diketones and Lewis bases - $\operatorname{Bpy}_{17-17}$ (5,5'diheptadecyl-2,2'-bipyridine) and Phen (1,10phenanthroline), see Figure 1.

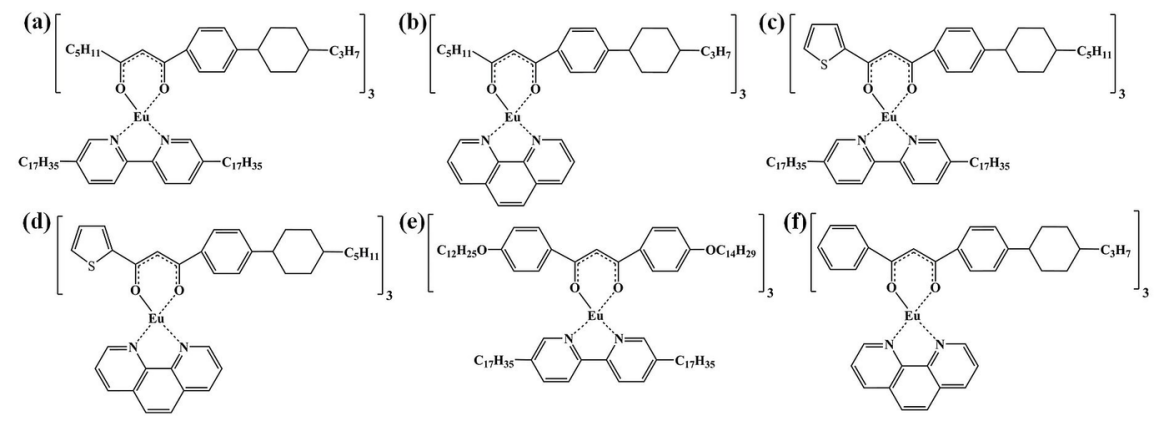

FIGURE 1 Optimized structures of the mesogenic $\mathrm{Eu}(\mathrm{III})$ complexes in the ground state:

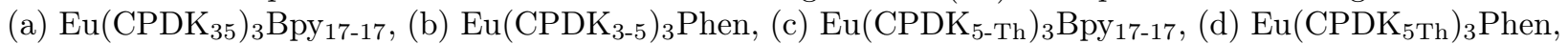
(e) $\mathrm{Eu}\left(\mathrm{DK}_{1214}\right)_{3} \mathrm{Bpy}_{1717}$, (f) $\mathrm{Eu}\left(\mathrm{CPDK}_{3-\mathrm{Ph}}\right)_{3} \mathrm{Phen}$

From Figure 1 one can see that all of the studied complexes have the coordination number 8 . Their coordination polyhedra includes the $\mathrm{Eu}(\mathrm{III})$ ion and 8 atoms from its first coordination sphere - six $\mathrm{O}$ centers of the $\beta$-diketones and two $\mathrm{N}$ centers of the Lewis bases. Initial geometries of the polyhedra were taken from the X-ray diffraction data for similar $\mathrm{Eu}(\mathrm{III})$ complexes without long terminal substituents ${ }^{[49-51]}$ from the Cambridge Structural Database. ${ }^{[52]}$

For the start of the optimization process the geometries of model Eu(III) complexes ${ }^{[49-51]}$ from the Cambridge Structural Database were modified by replacement of initial ligands by various substituted $\beta$ diketones and Lewis bases (Figure 1).

The presence of a heavy $\mathrm{Eu}(\mathrm{III})$ ion and a large number of atoms results in a high computational costs especially when optimizing the geometry of excited states. The geometry optimization of eight isomers for each of the studied $\mathrm{Eu}(\mathrm{III})$ complexes with different arrangement of $\beta$-diketones relative to the plane formed by the $\mathrm{Eu}(\mathrm{III})$ ion and the Lewis base ${ }^{[8,9,11,27]}$ was made. According to the calculations, the isomers with the crosswise arrangement of $\beta$ diketones have the lowest energy. In this energetically most advantageous arrangement of $\beta$ diketones the long alkyl substitutes do not sterically hinder each other. Therefore, only one stereoisomer for each of the coordination polyhedra of the studied $\mathrm{Eu}(\mathrm{III})$ complexes was considered. Exemplarily, eight optimized geometries of $\mathrm{Eu}\left(\mathrm{CPDk}_{35}\right)_{3}$ Phen isomers are presented in the Supporting Information (Table S1).

The resulting optimized structures and geometry parameters of the studied mesogenic Eu(III) complexes are shown in Figure 2. Steric hindrances caused by long alkyl substituents in the ligands led to insignificant distortions of the $\mathrm{Eu}(\mathrm{III})$ coordination polyhedra during optimization. Structural parameters of the optimized $\mathrm{Eu}(\mathrm{III})$ complexes, the average $\mathrm{Eu}-\mathrm{O}, \mathrm{C}-\mathrm{O}$, and $\mathrm{Eu}-\mathrm{N}$ bond lengths, as well as some characteristic angles are presented in Table 1. Coordination polyhedra of almost all studied Eu(III) complexes, as well as model compounds, were defined by the SHAPE program as a slightly distorted square antiprism. $\operatorname{Eu}\left(\mathrm{CPDK}_{35}\right)_{3} \mathrm{Phen}$, in contrast to $\mathrm{Eu}\left(\mathrm{CPDK}_{35}\right)_{3} \mathrm{Bpy}_{1717}$, has a triangular dodecahedron, as well as $\mathrm{Eu}\left(\mathrm{DK}_{1214}\right)_{3} \mathrm{Bpy}_{17-17}$ with long substituents in three $\beta$-diketones $\mathrm{DK}_{1214}$. They are all chiral and correspond to the $\mathrm{C}_{1}$ point group that 
often occurs in $\operatorname{Ln}(\mathrm{III})$ complexes with a coordination number of $8 .{ }^{[53-55]}$ Therefore, it can be assumed that Lewis base determines the type of coordination polyhedron in the some of the mesogenic $\mathrm{Eu}$ (III) complexes.
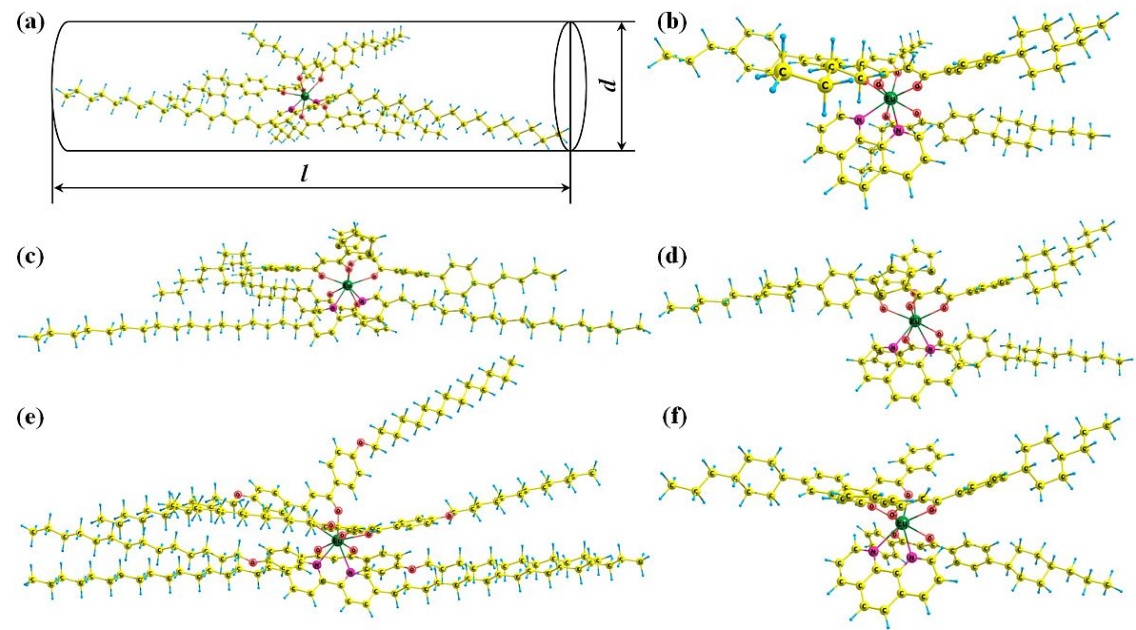

FIGURE 2 Optimized structures of the mesogenic $\mathrm{Eu}(\mathrm{III})$ complexes in the ground state: (a) $\mathrm{Eu}\left(\mathrm{CPDK}_{35}\right)_{3} \mathrm{Bpy}_{17-17}$, (b) $\mathrm{Eu}\left(\mathrm{CPDK}_{3-5}\right)_{3} \mathrm{Phen}$, (c) $\mathrm{Eu}\left(\mathrm{CPDK}_{5-\mathrm{Th}}\right)_{3} \mathrm{Bpy}_{17-17}$, (d) Eu(CPDK$\left.{ }_{5 \mathrm{Th}}\right)_{3} \mathrm{Phen}$, (e) $\mathrm{Eu}\left(\mathrm{DK}_{1214}\right)_{3} \mathrm{Bpy}_{1717}$, (f) $\mathrm{Eu}\left(\mathrm{CPDK}_{3-\mathrm{Ph}}\right)_{3} \mathrm{Phen}$

Structural parameters of the optimized mesogenic Eu(III) complexes (Table 1) are similar to those for model $\mathrm{Eu}(\mathrm{III})$ complexes with similar ligands without substituents. ${ }^{[4-51]}$ Average Eu-O bond lengths in the ground state vary through a small range $2.38-2.51 \AA$, whereas according to experimental data for model compounds they are $2.35 \AA$. Ground-state $\mathrm{Eu}-\mathrm{N}$ bond lengths are in the range $2.49-2.73 \AA$, which correlates with values of $2.58-2.64 \AA$ for model complexes. The average calculated angles correspond to the experimental ones within 4 degrees. Therefore, $\mathrm{Eu}-\mathrm{N}$ bond lengths in mesogenic complexes are $0.1 \AA$ longer than in model compounds7-9 (Table 1), while NEuN angles are 2-3 ${ }^{\circ}$ larger. The replacement of $\mathrm{CPDK}_{3-5}$ by $\mathrm{CPDK}_{5-\mathrm{Th}}$ and $\mathrm{CPDK}_{3-\mathrm{Ph}} \beta$ diketones leads to a decrease in the Eu-N bond length of complexes 4 and $\mathbf{5}$ by $0.20-0.13$ $\AA$ compared to complex $\mathbf{2}$. The average Eu-O bond length of complexes $\mathbf{1}$ and $\mathbf{2}$ with $\mathrm{CPDK}_{3-5}$, and $\mathbf{6}$ with $\mathrm{DK}_{12-14}$ is $0.1 \AA$ longer in contrast to complexes 3-5 with other $\beta$ diketones. This can be attributed to steric hindrances caused by the more branched geometry of $\mathrm{CPDK}_{3-5}$ and $\mathrm{DK}_{12-14}$ with long alkyl substituents, which prevents closer coordination of ligands.

TABLE 1 Average structural parameters (bond lengths in $\AA$, angles in degrees) of $\mathrm{Eu}(\mathrm{III})$ complexes in the ground $\left(\mathrm{S}_{0}\right)$ and triplet excited $\left(\mathrm{T}_{1}\right)$ states

\begin{tabular}{llllllllll}
\hline Complex $^{[\mathrm{a}]}$ & $\mathrm{Eu}-\mathrm{O}$ & $\mathrm{C}-\mathrm{O}$ & $\mathrm{Eu}-\mathrm{N}$ & $\mathrm{OEuO}^{[\mathrm{b}]}$ & $\mathrm{NEuN}$ & $\mathrm{NEuO}^{[\mathrm{c}]}$ & $l$ & $d$ & $l / c$ \\
\hline $\mathbf{1 ~ S}_{0}$ & 2.51 & 1.26 & 2.71 & 71.2 & 59.8 & 74.8 & 50.9 & 18.1 & 2.8 \\
$\mathrm{~T}_{1}[\mathrm{~d}]$ & 2.402 .59 & 1.251 .25 & 2.752 .72 & 69.969 .8 & 58.759 .5 & 73.274 .3 & 50.2 & 16.7 & 3.0 \\
$\mathbf{2} \mathrm{S}_{0}$ & 2.49 & 1.29 & 2.68 & 68.2 & 61.2 & 73.9 & 30.8 & 15.8 & 1.9 \\
$\mathrm{~T}_{1}$ & 2.402 .38 & 1.251 .29 & 2.522 .51 & 69.769 .8 & 59.559 .1 & 74.173 .2 & 30.2 & 15.4 & 1.9 \\
$\mathbf{3} \mathrm{S}_{0}$ & 2.40 & 1.27 & 2.58 & 71.3 & 60.1 & 73.5 & 50.1 & 19.9 & 2.5 \\
$\mathrm{~T}_{1}$ & 2.392 .38 & 1.251 .28 & 2.682 .73 & 69.468 .8 & 59.357 .8 & 73.773 .3 & 50.1 & 19.9 & 2.5 \\
$\mathbf{4} \mathrm{S}_{0}$ & 2.38 & 1.27 & 2.49 & 71.5 & 61.1 & 73.3 & 35.6 & 14.9 & 2.3 \\
$\mathrm{~T}_{1}$ & 2.392 .62 & 1.251 .25 & 2.682 .72 & 69.669 .2 & 60.060 .1 & 73.673 .4 & 35.6 & 14.9 & 2.3 \\
$\mathbf{5 ~ S}_{0}$ & 2.39 & 1.27 & 2.55 & 71.1 & 60.6 & 73.1 & 30.5 & 14.6 & 2.0 \\
$\mathrm{~T}_{1}$ & 2.392 .38 & 1.251 .28 & 2.712 .72 & 69.669 .3 & 59.758 .9 & 73.773 .2 & 30.8 & 14.7 & 2.1 \\
$\mathbf{6 ~}_{0}$ & 2.51 & 1.30 & 2.73 & 67.1 & 59.8 & 74.5 & 49.1 & 22.4 & 2.1
\end{tabular}




\begin{tabular}{|c|c|c|c|c|c|c|c|c|}
\hline Complex $^{[a]}$ & $\mathrm{Eu}-\mathrm{O}$ & $\mathrm{C}-\mathrm{O}$ & $\mathrm{Eu}-\mathrm{N}$ & $\mathrm{OEuO}^{[\mathrm{b}]}$ & NEuN & $\mathrm{NEuO}^{[\mathrm{c}]}$ & $l$ & $d$ \\
\hline $\mathrm{T}_{1}$ & 2.402 .52 & 1.251 .31 & 2.722 .70 & 68.167 .2 & 58.959 .5 & 73.975 .3 & 48.8 & 22.0 \\
\hline $7 \mathrm{~S}_{0}$ & 2.36 & 1.25 & 2.58 & 71.6 & 62.5 & 73.1 & 14.9 & 9.8 \\
\hline $8 \mathrm{~S}_{0}$ & 2.35 & 1.26 & 2.58 & 72.1 & 62.1 & 73.8 & 14.4 & 11.6 \\
\hline $9 \mathrm{~S}_{0}$ & 2.36 & 1.28 & 2.64 & 71.3 & 62.1 & 72.7 & 15.0 & 13.0 \\
\hline
\end{tabular}

[a] 1 - Eu( $\left(\mathrm{CPDK}_{35}\right)_{3} \mathrm{Bpy}_{17-17} ; 2-\mathrm{Eu}\left(\mathrm{CPDK}_{35}\right)_{3} \mathrm{Phen} ; 3$ - $\mathrm{Eu}\left(\mathrm{CPDK}_{5-\mathrm{Th}}\right)_{3} \mathrm{Bpy}_{17-17} ; 4$ - Eu(CPDK$\left.{ }_{5 \mathrm{Th}}\right)_{3} \mathrm{Phen}$; 5 - $\mathrm{Eu}\left(\mathrm{CPDK}_{3-\mathrm{Ph}}\right)_{3} \mathrm{Phen} ; 6$ - $\mathrm{Eu}\left(\mathrm{DK}_{12-14}\right)_{3} \mathrm{Bpy}_{17-17} ; 7$ - (2,2'-Bipyridyl)-tris(4,4,4-trifluoro-1-phenyl-1,3butanedionato)-europium(III); ${ }^{[49]} 8$ - (2,2'-Bipyridyl)-tris(2-thienoyltrifluoroacetonato)-europium(III); ${ }^{[50]} 9$ Tris(Di-benzoylmethanido)-(o-phenanthroline-N,N')-europium(III). ${ }^{[51]}[\mathrm{b}] \mathrm{OEuO}$ is the average angle between $\mathrm{Eu}(\mathrm{III})$ and $\mathrm{O}$ centers in a single $\beta$-diketone. [c] $\mathrm{NEuO}$ is the average angle between $\mathrm{N}$ centers, $\mathrm{Eu}$ (III) ions, and the nearest $\mathrm{O}$ center. [d] Separate excited state localization on $\beta$ diketones (top line) and Lewis bases (bottom line).

It was necessary to simulate equilibrium geometries of complexes in the ground state by high-level quantumchemical methods to ensure a sufficiently high reliability of the calculated structural data. The obtained structures were further applied for the optimization of excited-state geometries, the study of their correlations with parameters of polyhedra and intramolecular energy transfer pathways. The calculated IR spectra, NMR chemical shifts and subsequent energies of excited states are in good agreement with experimental data, which can confirm an accuracy of the selected model polyhedra and a successful optimization of complex geometries. Some examples of the calculated vibrational modes and chemical shifts compared with experimental data can be found in the Supporting Information (Tables S2 and S3). Chemical shifts were simulated with a relative error of $3 \%$ compared to experimental measurements. ${ }^{[8,9,30,37]}$

One of the main factors that allows one to divine LC properties prior to the synthesis of compounds is the values of anisotropy of geometry. This parameter can be calculated as the ratio between the long $(l)$ and the short $(d)$ inertial axes of the molecule $(l / d)$ (Figure 2). It changes from 4 to 8 for organic liquid crystals. Ligands with long alkyl substituents increase this ratio for LC Ln(III) complexes in comparison with other $\operatorname{Ln}(\mathrm{III})$ complexes to maximum value of 3.5. ${ }^{[8,9,11,27]}$ According to our earlier studies and calculations, ${ }^{[8,9,11,27]}$ the minimum value of the anisotropy parameter at which mesogenic $\operatorname{Ln}(\mathrm{III})$ complexes have LC properties equals 2.5. In this study, the anisotropy of geometry equals 2.81 and 2.52 for $\mathrm{Eu}\left(\mathrm{CPDK}_{35}\right)_{3} \mathrm{Bpy}_{17-17}$ and $\mathrm{Eu}\left(\mathrm{CPDK}_{5 \mathrm{Th}}\right)_{3} \mathrm{Bpy}_{17-17}$ (Table 1), respectively. For $\mathrm{Eu}\left(\mathrm{CPDK}_{35}\right)_{3} \mathrm{Phen}$, $\mathrm{Eu}\left(\mathrm{CPDK}_{5 \mathrm{Th}}\right)_{3} \mathrm{Phen}$, and $\mathrm{Eu}\left(\mathrm{CPDK}_{3 \mathrm{Ph}}\right)_{3}$ Phen this parameter reaches the values of 1.95, 2.39 and 2.09. According to experimental studies of these compounds, ${ }^{[9,30,56]}$ only complexes with Bpy ${ }_{17-17}$ exhibit LC properties. Upon the heating, $\mathrm{Eu}\left(\mathrm{CPDK}_{3-5}\right)_{3} \mathrm{Bpy}_{17-17}$ sequentially shows transitions to smectic and nematic mesophases, while $\mathrm{Eu}\left(\mathrm{CPDK}_{5 \mathrm{Th}}\right)_{3} \mathrm{Bpy}_{17-17}$ has only a smectic mesophase. In optimized structures (Table 1), the greatest contribution to the anisotropy parameter is made by $B_{17-17}$ and terminal alkyl substituents in $\beta$ diketones. Complexes $\mathbf{1}$ and $\mathbf{3}$ have the same Lewis base and similar $\boldsymbol{l}$ values, which significantly decrease for complexes 2and $\mathbf{4}$ when Bpy ${ }_{17-17}$ is replaced with Phen. Substitution of $\mathrm{CPDK}_{3-5}$ in complex $\mathbf{1}$ by $\mathrm{CPDK}_{5-\mathrm{Th}}$ in 3 has a greater effect on the $d$ value due to bulky substituents $\mathrm{C}_{4} \mathrm{H}_{3} \mathrm{~S}$ - in $\mathrm{CPDK}_{5 \text {-Th }}$. The largest $d$ value for $\mathrm{Eu}\left(\mathrm{CPDK}_{3-5}\right)_{3} \mathrm{Phen}$ in comparison with other complexes with Phen leads to the smallest $l / d$ ratio 1.95. Therefore, complexes $\mathbf{1}$ and $\mathbf{3}$ have an appropriatel / $d$ ratio that is above threshold of 2.5. This leads to the appearance of mesomorphism, while the complexes with Phen have an $l / d$ value below 2.5 and no LC properties. Complex6 shows smectic mesomorphism and the smallest anisotropy parameter (2.19) among studied LC complexes with Bpy ${ }_{17-17}$ due to long alkyl substituents in $\beta$ diketone $\mathrm{DK}_{12-14}$. The greater substituent' length in $\mathrm{DK}_{12-14}$ compared to other $\beta$ diketones increases both the length and the width of this molecule.

One of the pioneer studies of mesogenic rare-earth complexes with Schiff base ligands ${ }^{[57]}$ showed that the chain length in ligands has a little influence on the first coordination sphere of $\operatorname{Ln}(\mathrm{III})$ ion but determines the packing of complexes in the crystal structure. However, these long alkyl chains affect the geometry of the ligands during photoexcitation and the efficiency of the subsequent photophysical processes. 


\subsection{Optimized geometries of the triplet excited states}

In $\operatorname{Ln}(\mathrm{III})$ complexes the so-called "antenna effect" defines their luminescence efficiency and the intramolecular energy transfer from the ligand environment to the central ion. ${ }^{[1-9]}$ At the first stage of photoexcitation process of $\operatorname{Ln}(\mathrm{III})$ complexes, singlet excitation is localized on the ligand. The coincidence of the experimental absorption and excitation spectra of Ln(III) complexes with the corresponding spectra of individual ligands, ${ }^{[1-6,43,58,59]}$ as well as numerous experimental and theoretical studies ${ }^{[8,11,22-24]}$ confirm that excited states of $\operatorname{Ln}(\mathrm{III})$ complexes are localized on separate ligands. At the next stage, after fast nonradiative relaxation to the local minimum of the lowest singlet state, molecule deactivates either by fluorescence or by intersystem crossing to the nearest triplet state. Then nonradiative relaxation occurs to the local minimum of the lowest triplet state. Finally, the excitation energy transfers to the resonance levels of the $\operatorname{Ln}(\mathrm{III})$ ion, which nonradiatively relaxes to the radiative level and emits a photon at a certain wavelength. Structural relaxation of the excited states of $\operatorname{Ln}(\mathrm{III})$ complexes is several orders of magnitude faster than energy transfer processes. Therefore, it is necessary to take relaxation into account and optimize the geometry of the excited states.

In recent works, ${ }^{[60-62]}$ advanced DFT and $a b$ initio techniques have been used to numerically evaluate the energy transfer rates constants and demonstrated complex mechanisms of $\operatorname{Ln}(\mathrm{III})$ ions' sensibilization by surrounding ligands. Such mechanisms may include charge transfer states that mainly occur in molecules with electro-donating and electro-accepting units electronically connected via a conjugated skeleton ${ }^{[60]}$ and strongly depend on the solvent polarity. It is still difficult to unambiguously relate the $\mathrm{Eu}(\mathrm{III})$ sensitization to the triplet or charge transfer states.

Our previous experimental studies ${ }^{[7-9,30,37,43,56]}$ verified indirect sensitization mechanism in the simulated mesogenic $\mathrm{Eu}$ (III) complexes with saturated coordination sphere and did not show the presence of charge transfer excited states. Whereby in the studied complexes prevalent pathway includes intersystem crossing followed by energy transfer from triplet levels of ligands. It is also worth noting that the calculated (not for individual ligand molecules) triplet levels of the ligands in $\mathrm{Eu}(\mathrm{III})$ complexes coincide with the experimental values $^{[8,43,44]}$ obtained from the solvent-free phosphorescence spectra of vitrified Gd(III) complexes' films with the same ligand environment (Table 2).

The energy transfer efficiency and the luminescence quantum yield of $\operatorname{Ln}(\mathrm{III})$ complex are determined by the relative positions of the excited states of ligands and the $\operatorname{Ln}(\mathrm{III})$ ion. As was mentioned earlier, the greatest contribution to this process is made by the triplet levels of ligands. Therefore, on the next stage of the work the equilibrium geometries of the studied $\mathrm{Eu}(\mathrm{III})$ complexes in the ground state were used as the starting point for the calculations of the triplet excited states. According to our previous studies and literature data ${ }^{[8,11,22-24]}$ the excited states of $\operatorname{Ln}(\mathrm{III})$ complexes are localized on individual ligands. This statement can be also confirmed by the coincidence of the experimental absorption and excitation spectra of $\operatorname{Ln}(\mathrm{III})$ complexes with the corresponding spectra of individual ligands. ${ }^{[1-6,44,58,59]}$

Optimization of the geometries of the triplet excited states led to corresponding minima and localization of excitation on individual ligands. It was found that the first three triplet excited states are localized on $\beta$-diketones, and the last state - on the Lewis base. The average structural parameters of the studied $\mathrm{Eu}(\mathrm{III})$ complexes in the optimized geometries of their triplet excited states are presented in Table 1. Figures 3 and 4 show the optimized structures of $\mathrm{Eu}\left(\mathrm{CPDK}_{3-5}\right)_{3} \mathrm{Bpy}_{17-17}$ and $\mathrm{Eu}\left(\mathrm{CPDK}_{35}\right)_{3}$ Phen complexes in their ground and triplet excited states with triplet localization on $\beta$ diketone $\mathrm{CPDK}_{3-5}$ and Lewis base. Optimized geometries of other complexes can be found in the Supporting Information (Figure S1).

TABLE 2 Vertical energies $(\Delta \mathrm{E})$ in $\mathrm{Eu}(\mathrm{III})$ complexes and VDP characteristics in the optimized groundstate $\left(\mathrm{S}_{0}\right)$ and triplet $\left(\mathrm{T}_{1}\right)$ geometries with the reference of the excited state localization on separate ligands, intramolecular energy transfer $\left(\mathrm{W}_{\mathrm{ET}}\right)$ and back-transfer $\left(\mathrm{W}_{\mathrm{BT}}\right)$ rates, theoretical and experimental values of quantum yields (Q) 


\begin{tabular}{|c|c|c|c|c|c|c|c|c|c|c|}
\hline Complex $^{[a]}$ & Complex ${ }^{[a]}$ & Ligand & $\Delta \mathrm{E}, \mathrm{eV}$ & $\Delta \mathrm{E}, \mathrm{eV}$ & $\mathrm{W}_{\mathrm{ET}}, \mathrm{s}^{-1}$ & $\mathrm{~W}_{\mathrm{BT}}, \mathrm{s}^{-1}$ & $\mathrm{Q}, \%$ & $\mathrm{Q}, \%$ & $\mathrm{~V}_{\mathrm{VDP}}, \AA^{3}$ & $\mathrm{R}, \AA$ \\
\hline & & & Theor. & Exp. & & & Theor. & Exp. ${ }^{[47]}$ & & \\
\hline \multirow[t]{3}{*}{1} & $\mathrm{~S}_{0}$ & - & - & - & & & & & 12.41 & 1.436 \\
\hline & $\mathrm{T}_{1}$ & $\mathrm{CPDK}_{35}$ & 2.362 & $2.440^{[43]}$ & $2.04 \cdot 10^{7}$ & $2.28 \cdot 10^{2}$ & 15.0 & 11.0 & 13.25 & 1.468 \\
\hline & $\mathrm{T}_{1}$ & Bpy $_{17-17}$ & 2.790 & $2.870^{[44]}$ & & & & & 12.88 & 1.454 \\
\hline \multirow[t]{3}{*}{2} & $\mathrm{~S}_{0}$ & - & - & - & & & & & 12.44 & 1.437 \\
\hline & $\mathrm{T}_{1}$ & $\mathrm{CPDK}_{35}$ & 2.385 & $2.440^{[43]}$ & $3.07 \cdot 10^{8}$ & $0.11 \cdot 10^{2}$ & 32.6 & $30 \div 32$ & 13.33 & 1.471 \\
\hline & $\mathrm{T}_{1}$ & Phen & 2.606 & $2.684^{[44]}$ & & & & & 12.92 & 1.455 \\
\hline \multirow[t]{3}{*}{3} & $\mathrm{~S}_{0}$ & - & - & - & & & & & 12.37 & 1.435 \\
\hline & $\mathrm{T}_{1}$ & $\mathrm{CPDK}_{5-\mathrm{Th}}$ & 2.192 & $2.260^{[8]}$ & $1.22 \cdot 10^{7}$ & $2.73 \cdot 10^{5}$ & 10.1 & - & 13.24 & 1.465 \\
\hline & $\mathrm{T}_{1}$ & Bpy $_{17-17}$ & 2.803 & $2.870^{[44]}$ & & & & & 12.92 & 1.455 \\
\hline \multirow[t]{3}{*}{4} & $\mathrm{~S}_{0}$ & - & - & - & & & & & 12.39 & 1.435 \\
\hline & $\mathrm{T}_{1}$ & $\mathrm{CPDK}_{5-\mathrm{Th}}$ & 2.207 & $2.260^{[8]}$ & $5.82 \cdot 10^{7}$ & $1.08 \cdot 10^{5}$ & 24.1 & $20 \div 21$ & 13.27 & 1.469 \\
\hline & $\mathrm{T}_{1}$ & Phen & 2.617 & $2.684^{[44]}$ & & & & & 12.90 & 1.455 \\
\hline \multirow[t]{3}{*}{5} & $\mathrm{~S}_{0}$ & - & - & - & & & & & 12.40 & 1.436 \\
\hline & $\mathrm{T}_{1}$ & $\mathrm{CPDK}_{3-\mathrm{Ph}}$ & 2.311 & $2.380^{[43]}$ & $3.88 \cdot 10^{7}$ & $1.68 \cdot 10^{3}$ & 29.7 & $25 \div 27$ & 12.93 & 1.456 \\
\hline & $\mathrm{T}_{1}$ & Phen & 2.605 & $2.684^{[44]}$ & & & & & 12.89 & 1.455 \\
\hline \multirow[t]{3}{*}{6} & $\mathrm{~S}_{0}$ & - & - & - & & & & & 14.18 & 1.502 \\
\hline & $\mathrm{T}_{1}$ & $\mathrm{DK}_{12-14}$ & 2.294 & $2.375^{[37]}$ & $6.42 \cdot 10^{7}$ & $3.71 \cdot 10^{5}$ & 17.1 & $20 \div 23$ & 14.93 & 1.896 \\
\hline & $\mathrm{T}_{1}$ & Вpy $_{17-17}$ & 2.784 & $2.870^{[44]}$ & & & & & 14.56 & 1.701 \\
\hline
\end{tabular}

[a] 1 - Eu( $\left(\mathrm{CPDK}_{35}\right)_{3} \mathrm{Bpy}_{17-17} ; 2-\mathrm{Eu}\left(\mathrm{CPDK}_{35}\right)_{3} \mathrm{Phen} ; 3$ - Eu($\left(\mathrm{CPDK}_{5-\mathrm{Th}}\right)_{3} \mathrm{Bpy}_{17-17} ; 4$ - Eu( $\left(\mathrm{CPDK}_{5 \mathrm{Th}}\right)_{3} \mathrm{Phen}$; 5 - $\mathrm{Eu}\left(\mathrm{CPDK}_{3-\mathrm{Ph}}\right)_{3} \mathrm{Phen} ; 6$ - $\mathrm{Eu}\left(\mathrm{DK}_{12-14}\right)_{3} \mathrm{Bpy}_{17-17}$.
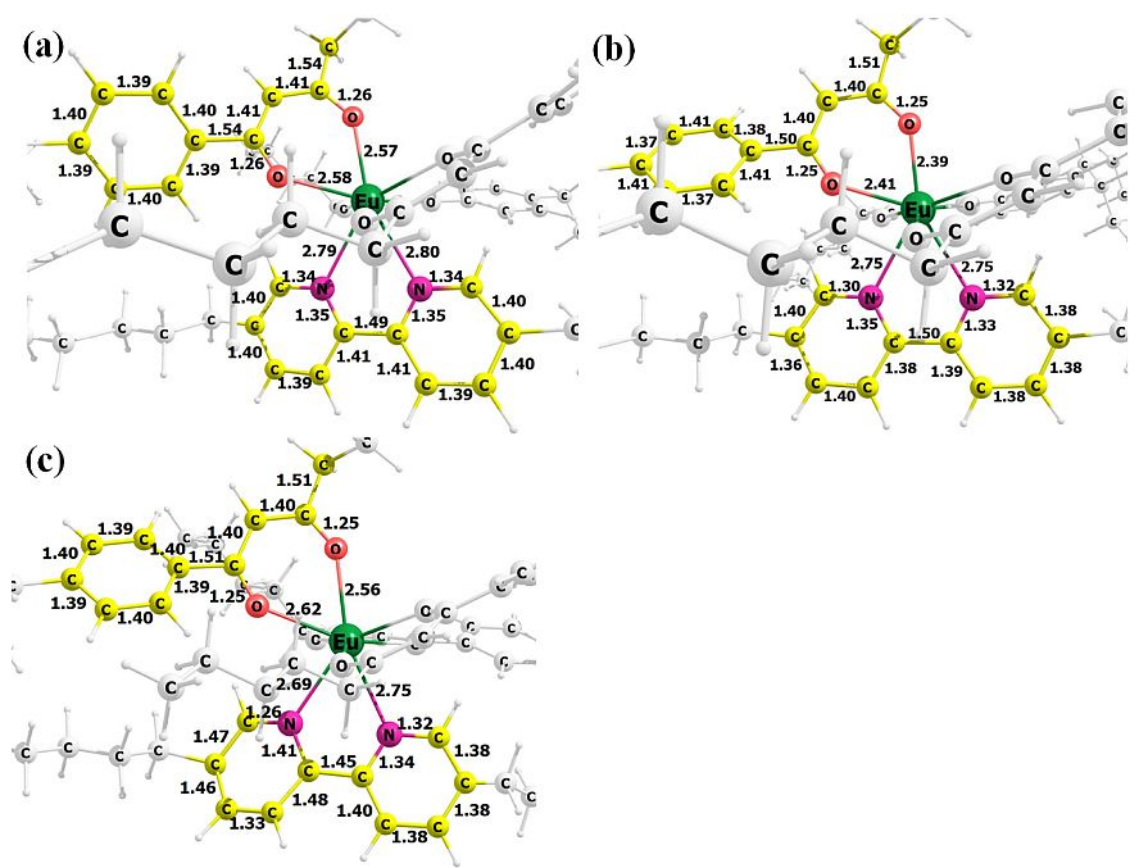

FIGURE 3 Optimized ground (a) and triplet excited state structures of $\mathrm{Eu}\left(\mathrm{CPDK}_{3-5}\right)_{3} \mathrm{Bpy}_{17-17}$ with triplet localization on $\beta$-diketone $\mathrm{CPDK}_{3-5}$ (b) and Lewis base Bpy $17-17$ (c) 

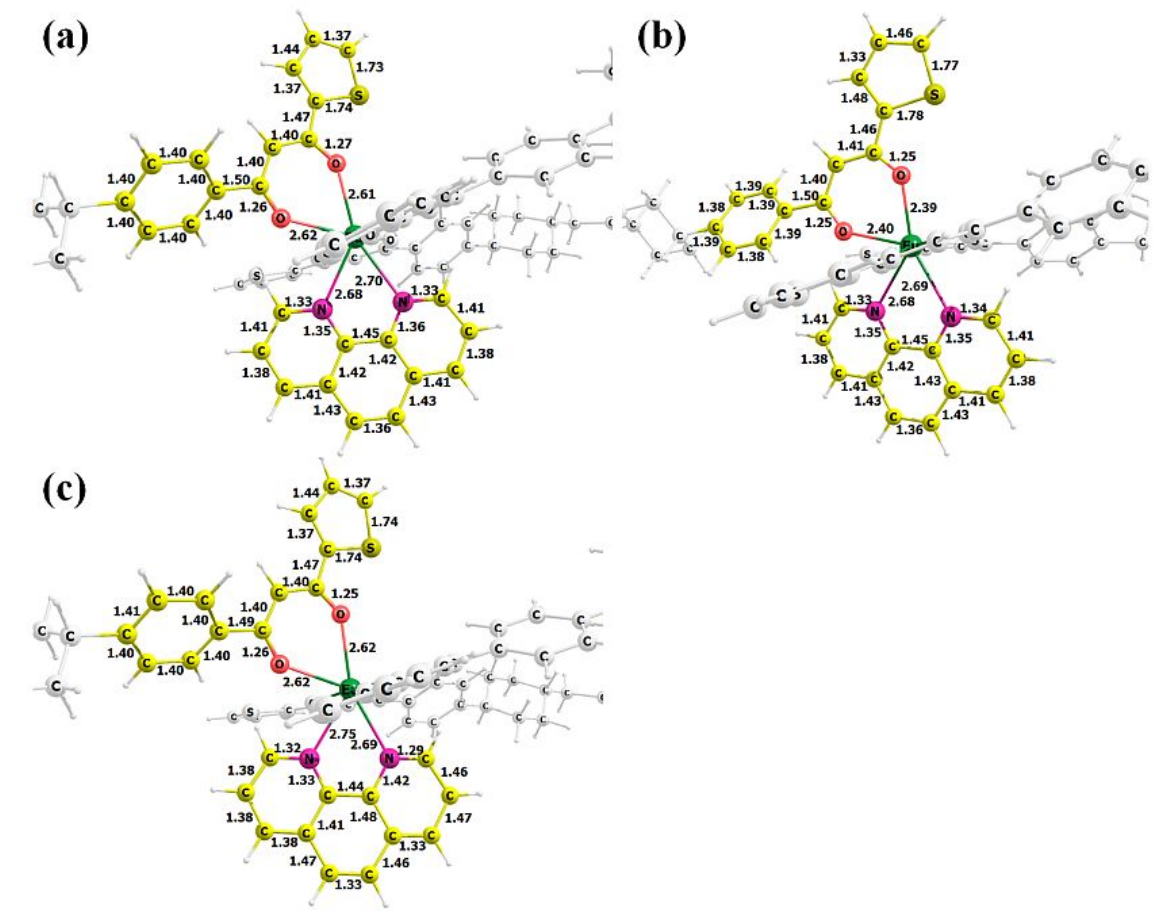

FIGURE 4 Optimized ground (a) and triplet excited state structures of $\mathrm{Eu}\left(\mathrm{CPDK}_{5-\mathrm{Th}}\right)_{3} \mathrm{Phen}$ with triplet localization on $\beta$-diketone $\mathrm{CPDK}_{5-\mathrm{Th}}(\mathrm{b})$ and Lewis base Phen (c)

Differences in the structure of the ground and excited states can determine the efficiency of energy transfer process and the emission intensity. It was found that localization of excitation on the same ligand in different $\mathrm{Eu}(\mathrm{III})$ complexes leads to similar geometry changes (Figures $3 \mathrm{~b}$ and $4 \mathrm{~b}$ ). The triplet-localization of excitation on $\beta$-diketone (Figures $3 \mathrm{~b}$ and $4 \mathrm{~b}$ ) resulted in insignificant changes of bond lengths by $~ 0.1$ $\AA$ (Table 2) compared with the ground state (Figures $3 \mathrm{a}$ and $4 \mathrm{a}$ ). At the same time, the dihedral angles between non-alkyl substituents and $\mathrm{C}=\mathrm{O}$ bonds in $\beta$ diketones changed by $10-13^{\circ}$. In the case of Bpylocalized excitations, the $\mathrm{C}-\mathrm{H}$ bond in position 5 of the pyridine ring came out of the plane by $20^{\circ}$ (Figure 3c). But when triplet excitation was localized on Phen, this ligand remained its planar geometry (Figure 4c). Such significant structural deformations of $\mathrm{Eu}(\mathrm{III})$ complexes with Bpy can lead to a noticeable shift in the energy minima of the ground and excited states and even to the crossing of their potential curves. Consequently, during the relaxation of the excited state, the molecule can transfer to the curve of the ground state and relax to its stationary state without any emission. On the contrary, the rigid structure of the $\mathrm{Eu}(\mathrm{III})$ complexes with Phen minimizes the nonradiative deactivation and increases their emission efficiency. Thus, it can be assumed that in $\mathrm{Eu}$ (III) complexes with $\beta$-diketones and Lewis bases, the main role in energy transfer is played by three $\beta$-diketones due to their more flexible geometry compared to Lewis bases. Similar structural changes of excited ligands can be found in literature. ${ }^{[11,16,18,63]}$

Table 2 shows the results of the calculated triplet energies of $\mathrm{Eu}(\mathrm{III})$ complexes with excitation localization on individual ligands. Similar values were obtained for triplet localization on the same ligands in different $\mathrm{Eu}(\mathrm{III})$ complexes. For instance, the excited levels for triplet excitation of Bpy $\mathrm{B}_{17-17}$ in complexes $\mathbf{1}$ and $\mathbf{3}$ differ by $0.03 \mathrm{eV}$ (Table 2). The same distinction was obtained for $\mathrm{CPDK}_{5-\mathrm{Th}}$ in complexes $\mathbf{3}$ and $\mathbf{4}$, and even smaller differences were observed for other ligands. Therefore, it can be assumed that the excited states localized on the corresponding ligand are practically independent of other ligands in the complex.

The inner $4 \mathrm{f}$ shell of $\operatorname{Ln}(\mathrm{III})$ is shielded from the influence of the ligand environment by the outer $5 s$ and $5 p$ shells. This leads to quite narrow emission bands of $4 f$ transitions which have the same wavelengths 
for different complexes of a given $\operatorname{Ln}(\mathrm{III}) \cdot{ }^{[1-6]}$ Therefore, the $4 f$ levels of $\mathrm{Eu}(\mathrm{III})$ can be obtained from the experimental data ${ }^{[64,65]}$ due to unaffordable computational costs for their calculation for the studied $\mathrm{Eu}(\mathrm{III})$ complexes with huge ligands.

Table 2 also presents the calculated rates of the intramolecular forward and back energy transfer from the averaged triplet levels of ligands to the resonance levels of $\mathrm{Eu}(\mathrm{III})$, as well as the theoretically predicted quantum yields in comparison with the experimental ones. ${ }^{[4]}$ As can be seen from Table 2, complexes $\mathrm{Eu}\left(\mathrm{CPDK}_{35}\right)_{3}$ Phen and $\mathrm{Eu}\left(\mathrm{CPDK}_{3 \mathrm{Ph}}\right)_{3}$ Phen are characterized by the highest rates of forward energy transfer and small contributions of the backward processes, which leads to their remarkable emission efficiency according to the values of luminescence quantum yields (32.6 and $29.7 \%$, respectively). Complexes with $\mathrm{Bpy}_{17-17}$, on the contrary, are characterized by insubstantial luminescence efficiency and intermolecular energy transfer, which can be explained by the analysis of their energy transfer channels.

The triplet level of Bpy $17-17$-localized excitation (2.790 eV in complex 1$)$ is situated between the ${ }^{5} \mathrm{D}_{2}(2.667$ $\mathrm{eV})$ and $^{5} \mathrm{D}_{3}(3.024 \mathrm{eV})$ levels of $\mathrm{Eu}(\mathrm{III}) .{ }^{[64,65]}$ Therefore, in complex 1energy transfer will occur from the Bpy $_{17-17}$ triplet level of $2.797 \mathrm{eV}$ to the ${ }^{5} \mathrm{D}_{2}$ multiplet of $\mathrm{Eu}(\mathrm{III})$. Such position of the triplet level can lead to energy losses due to additional stages of interligand transfer or nonradiative transfer between different multiplet of ${ }^{5} \mathrm{D}_{\mathrm{j}}$ state. The triplet levels of $\beta$-diketones $\mathrm{CPDK}_{5 \mathrm{Th}}(2.192$ and $2.207 \mathrm{eV}$ in complexes3 and 4 ) and $\mathrm{DK}_{12-14}(2.294 \mathrm{eV}$ in complex 6 with the experimental value of $2.375 \mathrm{eV})$ are too close to the ${ }^{5} \mathrm{D}_{1}$ multiplet $(2.359 \mathrm{eV})$ and can partially transfer energy to the ${ }^{5} \mathrm{D}_{0}$ level $(2.141 \mathrm{eV})$. Unfortunately, the presence of this energy transfer channel and wide energy gap between these two states (ligand's triplet level and ${ }^{5} \mathrm{D}_{0}$ ) will increase the probability of energy losses due to energy back transfer, molecule deactivation by ligands' phosphorescence, energy dispersion and decrease of the $\mathrm{Eu}(\mathrm{III})$ luminescence efficiency. Therefore, $\mathrm{Eu}\left(\mathrm{CPDK}_{5 \mathrm{Th}}\right)_{3} \mathrm{Bpy}_{17-17}$ is characterized by the lowest quantum yield $(10.1 \%)$ among the studied objects. On the contrary, the triplet levels of $\mathrm{CPDK}_{3-5}(2.362 \mathrm{eV}$ in complex $\mathbf{1}), \mathrm{CPDK}_{3-\mathrm{Ph}}(2.311 \mathrm{eV}$ in complex $\mathbf{5}$ ) and Phen (2.606 eV in complex 2 ) are in resonance with the ${ }^{5} \mathrm{D}_{1}$ multiplet and can participate in efficient energy transfer to $\mathrm{Eu}(\mathrm{III})$.

According to experimental works ${ }^{[44,66-68]}$ and general theoretical assumptions, ${ }^{[1-6,11,16]}$ complexes with triplet levels located between ${ }^{5} \mathrm{D}_{1}$ and ${ }^{5} \mathrm{D}_{2}$ multiplets of $\mathrm{Eu}(\mathrm{III})$ potentially have the highest emission intensity and smaller energy losses. This can be explained by effective energy transfer from the triplet level of ligand to ${ }^{5} \mathrm{D}_{1}$ multiplet of $\mathrm{Eu}(\mathrm{III})$ which is located above the emitting ${ }^{5} \mathrm{D}_{0}$. In the case of resonant energy transfer from the ligand to $\mathrm{Eu}(\mathrm{III})$, the contribution of the back transfer from the ion to ligand is quite large. The process of $\mathrm{Eu}(\mathrm{III})$ phosphorescence is relatively slow, and ion can return energy to the ligand. But when energy can be transferred to the upper energy level than the emitting one, back transfer competes with the nonradiative relaxation process of the excited ion due to small energy gaps between ${ }^{5} \mathrm{D}_{\mathrm{j}}$ multiplets. After such relaxation, the resonance between the ligand's triplet level and the central ion is disturbed, therefore energy back transfer becomes impossible. Among the studied $\mathrm{Eu}(\mathrm{III})$ complexes, $\mathrm{Eu}\left(\mathrm{CPDK}_{35}\right)_{3} \mathrm{Phen}$ and $\mathrm{Eu}\left(\mathrm{CPDK}_{3 \mathrm{Ph}}\right)_{3} \mathrm{Phen}$ meet these requirements.

\subsection{Voronoi-Dirichlet polyhedra of the triplet excited states}

The Voronoi-Dirichlet polyhedra method allows one to reveal the features of the coordination environment of the central ion and its effect on intermolecular interactions. The VDP parameters can be used to identify the valence state of the ion, crystal-chemical stability, phase transitions of the first and second order, as well as the LC behavior of $\mathrm{Ln}(\mathrm{III})$ coordination compounds. They were calculated for the $\mathrm{Eu}$ (III) complexes in the optimized geometries of their ground and triplet excited states. ${ }^{[69,70]}$ The resulting VDP shapes (Figure 5 ) are convex polyhedra with surfaces formed by planes passing perpendicularly through the midpoints of the $\mathrm{Eu}-\mathrm{O}$ and $\mathrm{Eu}-\mathrm{N}$ bonds. 

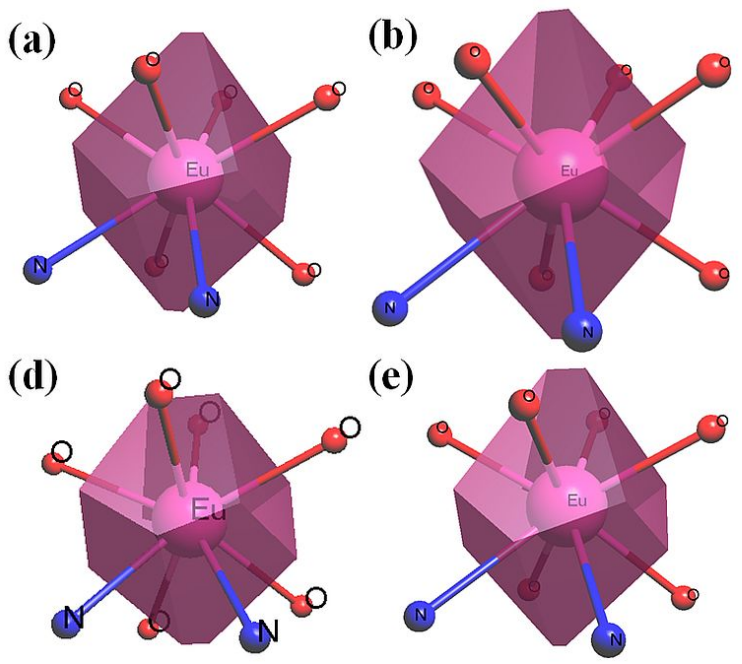
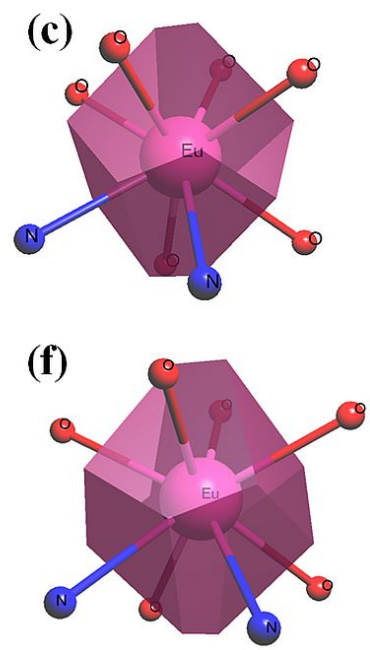

FIGURE 5 Shapes of the VDP of the optimized $\mathrm{Eu}(\mathrm{III})$ complexes: (a) $\mathrm{Eu}\left(\mathrm{CPDK}_{3-5}\right)_{3} \mathrm{Bpy}_{17-17}$, (b) $\mathrm{Eu}\left(\mathrm{CPDK}_{3-5}\right)_{3} \mathrm{Phen},(\mathrm{c}) \mathrm{Eu}\left(\mathrm{CPDK}_{5 \mathrm{Th}}\right)_{3} \mathrm{Bpy}_{17-17}$, (d) $\mathrm{Eu}\left(\mathrm{CPDK}_{5-\mathrm{Th}}\right)_{3} \mathrm{Phen}$, (e) $\mathrm{Eu}\left(\mathrm{CPDK}_{3 \mathrm{Ph}}\right)_{3} \mathrm{Phen}$, (f) $\mathrm{Eu}\left(\mathrm{DK}_{12-14}\right)_{3} \mathrm{Bpy}_{17-17}$

The asymmetry of the nearest environment of $\mathrm{Eu}(\mathrm{III})$ can be qualitatively evaluated by the $G_{3}$ parameter which is the normalized second moment of inertia of the VDP. ${ }^{[71]}$ This parameter determines the degree of nonsphericity or distortion of the coordination shell and considers the shape of the molecule, its chemical composition, and intermolecular interactions between the molecule and its environment. High degree of sphericity of the central atom's environment is characterized by small values of $G_{3}$, while high values mean significant asymmetry in the arrangement of ligands.

According to the calculated data (Table 2), the optimized geometries of $\mathrm{Eu}(\mathrm{III})$ complexes in the ground state have similar values of $G_{3}$ in the range $0.0812-0.0828$, while in the triplet excited state this parameter varies from 0.0811 to 0.0838 . Typical $G_{3}$ values for $\operatorname{Ln}(\mathrm{III})$ with a simpler ligand environment are in the range 0.081-0.085. ${ }^{[70,72]}$ The lowest $G_{3}$ parameters for optimized ground state structures correspond to $\mathrm{Eu}\left(\mathrm{DK}_{12-14}\right)_{3} \mathrm{Bpy}_{17-17}(0.0812)$ and $\mathrm{Eu}\left(\mathrm{CPDK}_{3-5}\right)_{3} \mathrm{Phen}(0.0813)$. The replacement of $\mathrm{CPDK}_{3-5}$ in this complex 2 by $\mathrm{CPDK}_{3-\mathrm{Ph}}$ and $\mathrm{CPDK}_{5-\mathrm{Th}}$ in complexes 4 and $\mathbf{5}$ leads to a slight increase of $G_{3}$ to 0.0820 and 0.0821 and, apparently, to a greater asymmetry in the arrangement of ligands. This effect can be explained by conjugation between $\mathrm{C}_{6} \mathrm{H}_{5}$ - substituents in $\mathrm{CPDK}_{3-\mathrm{Ph}}$ and $\mathrm{C}_{4} \mathrm{H}_{3} \mathrm{~S}$ - in $\mathrm{CPDK}_{5-\mathrm{Th}}$.

When triplet excitation is localized on $\beta$-diketones, $G_{3}$ consistently increases (Table 2 ) due to a decrease in the uniformity of the molecule's structure, significant distortions of coordination polyhedra, and thermal vibrations of molecules upon photoexcitation. A more significant increase in $G_{3}$ is observed for complexes 2 , 4 and $\mathbf{5}$ with Phen. Complexes 3 and $\mathbf{6}$ with $\mathrm{CPDK}_{5-\mathrm{Th}}$ and $\mathrm{DK}_{12-14}$ have the highest $G_{3}$ values - 0.0833 and 0.0838 , while the lowest $G_{3}$ value (0.0811) corresponds to complexes2 and $\mathbf{6}$ with the localization of the excitations on Lewis bases.

For optimized structures with the excited state localization on Lewis base, $G_{3}$ parameter slightly decreases in comparison with the ground state. This indicates insignificant changes in the geometry of Eu(III) complexes and small distortions of coordination polyhedra in photophysical processes involving Bpy $17-17$ and Phen. Thus, photoexcitation of $\beta$-diketones leads to a greater change in the coordination sphere of the $\mathrm{Eu}(\mathrm{III})$ complexes. Previously it was shown that the localization of the triplet excitation on $\beta$-diketones causes more significant changes in structural parameters in comparison with Lewis bases. Consequently, while the structure of the Lewis base regulates the LC properties of mesogenic $\mathrm{Eu}$ (III) complexes, the choice of a certain $\beta$ diketone significantly affects their absorbance and emission efficiency. 
The volume of VDP $\left(V_{V D P}\right)$ is related to the valence state of the central atom, the nature and electronegativity of ligand atoms in polyhedron. ${ }^{[69,70,73]}$ All optimized ground state structures of $\mathrm{Eu}(\mathrm{III})$ complexes have similar VDP volumes (Table 2) due to identical atoms (six $\mathrm{O}$ from $\beta$-diketones and two $\mathrm{N}$ from the Lewis base) that form bonds with the $\mathrm{Eu}(\mathrm{III})$ ion in similar ligands.

Upon photoexcitation, an increase in $V_{V D P}$ is observed by $4 \%$ for triplet state localization on Lewis bases and by $4-7 \%$ for $\beta$-diketone localized excited states. Such changes indicate significant distortions in the geometry of the polyhedra.

The radius $R$ of a certain sphere with a volume equal to the volume of the VDP describes the state of the central atom in a certain environment. $R$ is constant for an ion in the same oxidation state, surrounded by atoms of the same type. ${ }^{[74]}$ Therefore, its values are very similar for all the studied $\mathrm{Eu}(\mathrm{III})$ complexes in the ground state (Table 2). Since $R$ also correlates with the energy of intermolecular interactions between molecule and its environment, it increases upon photoexcitation. Some of the highest values are observed for triplet excitation on $\beta$-diketones in complexes $\mathbf{2}$ and $\mathbf{4}$, which do not have LC properties. Significant distortions in the coordination polyhedron of $\mathrm{Eu}\left(\mathrm{DK}_{1214}\right)_{3} \mathrm{Bpy}_{1717}$ with three branchy $\beta$-diketones result in notable VDP' volume of $14.18 \AA^{3}$ and radius of $1.896 \AA$.

Therefore, luminescence, LC and magnetic properties of the Ln(III) complexes are determined not only by the ligand environment. Such factors as Ln(III) ions' nature, interactions between ions and ligands, the crystal field potential and the type of polyhedra can make a big difference on their behaviour. The relationship between the type of the coordination polyhedron of various $\operatorname{Ln}(\mathrm{III})$ complexes and their roomtemperature magnetic anisotropy (the difference between magnetic susceptibilities parallel and perpendicular to the magnetic field director) was reported. ${ }^{[10]}$ Authors noticed the influence of the Ln(III) ion nature and the degree of the distortion of high-symmetry polyhedra on the sign and magnitude of the magnetic anisotropy. Since the magnetic susceptibility of high-symmetry polyhedra is isotropic their magnetic anisotropy is zero in the absence of distortions. Therefore low-symmetry polyhedra of the studied mesogenic Eu(III) complexes may result in significant magnetic anisotropy at room temperature and easy alignment even in a weak in external magnetic field.

\section{CONCLUSIONS}

Quantum-chemical simulation of six mesogenic $\mathrm{Eu}(\mathrm{III})$ complexes with various substituted $\beta$ diketones and Lewis bases, $\mathrm{Eu}\left(\mathrm{CPDK}_{3-5}\right)_{3} \mathrm{Bpy}_{17-17}(1), \quad \mathrm{Eu}\left(\mathrm{CPDK}_{3-5}\right)_{3} \mathrm{Phen} \quad(2), \quad \mathrm{Eu}\left(\mathrm{CPDK}_{5 \mathrm{Th}}\right)_{3} \mathrm{Bpy}_{1717}(3)$, $\mathrm{Eu}\left(\mathrm{CPDK}_{5 \mathrm{Th}}\right)_{3} \mathrm{Phen}(4), \mathrm{Eu}\left(\mathrm{CPDK}_{3 \mathrm{Ph}}\right)_{3} \mathrm{Phen}(5)$ and $\mathrm{Eu}\left(\mathrm{DK}_{12-14}\right)_{3} \mathrm{Bpy}_{17-17}$ (6) allowed us to determine relationships between their molecular structure, the anisotropy of geometry, LC properties and luminescence efficiency.

Optimization of the geometry of triplet excited states led to the localization of excitation on individual ligands and significant geometric changes in the corresponding ligands. The calculated values agree well with experimental data. It was found that, due to the separate localization of excitations on individual ligands in $\mathrm{Eu}$ (III) complex, the calculated excited states are practically independent on the presence of other ligands in the complex. On the basis of the calculated triplet excited states and intramolecular energy transfer rates, the main channels of intramolecular energy transfer in $\mathrm{Eu}(\mathrm{III})$ complexes were determined and their luminescence efficiency and quantum yields were estimated.

It is found that, in the case of $\mathrm{Bpy}_{17-17}$-localized excitations, energy transfer occurs from the triplet level of the ligand to the ${ }^{5} \mathrm{D}_{2}$ level of $\mathrm{Eu}$ (III). From the Phen-localized triplet states, excitation energy transfers to the ${ }^{5} \mathrm{D}_{1}$ multiplet of $\mathrm{Eu}(\mathrm{III})$, as well as in the case of $\beta$-diketones $\mathrm{CPDK}_{35}$ and $\mathrm{CPDK}_{3-\mathrm{Ph}}$. According to experimental studies, ${ }^{[66-68]}$ the highest emission efficiency usually corresponds to $\mathrm{Eu}(\mathrm{III})$ complexes when energy transfer occurs from ligands to the ${ }^{5} \mathrm{D}_{1}$ level, which is located above the ${ }^{5} \mathrm{D}_{0}$ emitting level. In our case, complexes 2 and 5 with Phen best fit this experimental rule. Furthermore, the more rigid geometry of

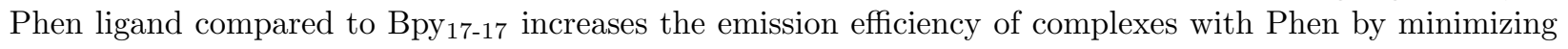


the contribution of nonradiative deactivation to the energy transfer process. At the same time, complexes 1 and 3 with Bpy 17-17 $_{17}$ have the highest anisotropy parameters above the LC properties demonstration threshold ${ }^{[8,9,11,27]}$ due to alkyl substituents in Lewis base and $\beta$ diketones.

The parameters of VDP of the studied $\mathrm{Eu}(\mathrm{III})$ complexes in the optimized geometries of their ground and triplet excited states were calculated and evaluated. The smallest $G_{3}$ parameters of about 0.0817 and 0.0813 were obtained for complexes 1 and 2 with $\mathrm{CPDK}_{35}$ in the ground state. Complex 3 has the highest $G_{3}$ value of 0.0828 possibly due to the conjugation between $\mathrm{C}_{4} \mathrm{H}_{3} \mathrm{~S}$ - heterocycles in $\mathrm{CPDK}_{5 \mathrm{Th}}$. High values of $G_{3}$ determine the asymmetry in the arrangement of ligands and characterize a decrease of directed intermolecular interactions. For $\mathrm{Eu}(\mathrm{III})$ complexes 4 and 5 that results in the absence of LC behavior.

The changes in the coordination polyhedra of the complexes during their photoexcitation were identified. The localization of the triplet excitation on $\beta$-diketones results in the increase of the $\mathrm{G}_{3}$ parameter in comparison with the ground state. This indicates significant distortions of the geometry of polyhedra and asymmetry in the arrangement of ligands. The optimization of the geometry of excited states also lead to more significant changes in the geometry of $\beta$-diketones compared to the excitations on Lewis bases. Such low-symmetry polyhedra may further result in significant magnetic anisotropy and easy alignment of the studied complexes even in a weak external magnetic field. On the other side the localization of the excitation on the Lewis base lead to a slightly decrease of the $\mathrm{G}_{3}$ parameter. This is can be explained by insignificant changes in the geometry of Bpy $17-17^{-}$or Phen-localized excitations and small distortions in the coordination polyhedron. The more significant increase in $\mathrm{G}_{3}$ was observed for complexes with Phen which do not exhibit LC properties. Significant asymmetry of polyhedra and lower forces of intermolecular interactions apparently lead to the absence of LC properties for complexes with Phen. Therefore, while the structure of the Lewis base regulates the presence of LC properties in mesogenic Eu (III) complexes, the selection of a certain $\beta$ diketone will significantly affect the efficiency of light absorption. The calculated IR spectra, triplet excited states, and geometric anisotropy of the $\mathrm{Eu}(\mathrm{III})$ complexes are in good agreement with the corresponding experimental data. This confirms the revealed dependencies and the adequacy of the chosen simulation technique.

Therefore, the main factors ( $\operatorname{Ln}(\mathrm{III})$, coordination polyhedra, ligands and their substitutes) influencing the multifunctional behavior of the studied metallomesogens in the excited state were established. According to the described dependences and results, their LC properties mostly depend on the ligand environment, the magnetic properties are determined by the structural features of the coordination polyhedra, and both factors can affect the luminescence efficiency. Although the described effects were observed for six exemplary mesogenic $\mathrm{Eu}$ (III) complexes with $\beta$ diketones and Lewis bases, the proposed simulation methodology has a wide scope. It can be effectively used to study other components of multifunctional materials, including their structure and luminescence efficiency, to predict liquid-crystalline properties and magnetic anisotropy of metal containing LC or supramolecularly organized compounds with promising optical and magnetic properties.

\section{FUNDING INFORMATION}

The work was supported by a project No. GSGK-0064/21. This project is being implemented by the winner of the Master's program faculty grant competition of the Vladimir Potanin fellowship program.

\section{RESEARCH RESOURCES}

Quantum-chemical calculations were performed using the facilities of the Joint Supercomputer Center of Russian Academy of Sciences. This study was carried out using the equipment of the Center for Collective Use "Nanomaterials and Nanotechnology" of the Kazan National Research Technological University. 


\section{REFERENCES}

1. J.-C. G. Bünzli, In Handbook on the Physics and Chemistry of Rare Earths; J.-C. G. Bünzli, V. K. Pecharsky, Eds.; Elsevier, Amsterdam,2016, Vol. 50, p. 141.

2. J.-C. G. Bünzli, Trends Chem. $2019,1,751$.

3. J. Zhou, J. L. Leaño Jr., Z. Liu, D. Jin, K.-L. Wong, R.-S. Liu, J.-C. G. Bünzli, Small 2018 , 14 , 1801882.

4. S. Guerra, T. Dutronc, E. Terazzi, K.-L. Buchwalder, L. Guenee, R. Deschenaux, S. V. Eliseeva, S. Petoud, C. Piguet, Coord. Chem. Rev. $2017,340,79$.

5. M. F. Reid, In Handbook on the Physics and Chemistry of Rare Earths; J.-C. G. Bünzli, V. K. Pecharsky, Eds.; Elsevier, Amsterdam,2016, Vol. 50, p. 47.

6. A. N. Carneiro Neto, E. E. S. Teotonio, G. F. de Sá, H. F. Brito, J. Legendziewicz, L. D. Carlos, M. C. F. C. Felinto, P. Gawryszewska, R. T. Moura Jr., R. L. Longo, W. M. Faustino, O. L. Malta, In Handbook on the Physics and Chemistry of Rare Earths; J.-C. G. Bünzli, V. K. Pecharsky, Eds.; Elsevier, Amsterdam, 2019 , Vol. 56, p. 55.

7. D. V. Lapaev, V. G. Nikiforov, V. S. Lobkov, A. A. Knyazev, A. S. Krupin, Y. G. Galyametdinov, J. Photochem. Photobiol. A2019, 382, 111962.

8. A. A. Knyazev, A. S. Krupin, K. A. Romanova, Yu. G. Galyametdinov, J. Coord. Chem. 2016 , 69 , 1473 .

9. A. A. Knyazev, M. E. Karyakin, K. A. Romanova, B. Heinrich, B. Donnio, Yu. G. Galyametdinov, Eur. J. Inorg. Chem. $2017,2017,639$.

10. V. S. Mironov, Yu. G. Galyametdinov, A. Ceulemans, C. Görller-Walrand, K. Binnemans, J. Chem. Phys. 2002, 116, 4673.

11. K. A. Romanova, Yu. G. Galyametdinov, Liq. Cryst. and their Appl. 2016 , $16,80$.

12. R. O. Freire, A. M. Simas, Int. J. Quantum Chem. $2011,111,1734$.

13. M. A. M. Filho, J. D. L. Dutra, G. B. Rocha, R. O. Freire, A. M. Simas, RSC Adv. 2013 , 3 , 16747.

14. D. Aravena, M. Atanasov, F. Neese, Inorg. Chem. $2016,55,4457$.

15. I. A. Kurbatov, A. G. Mirochnik, N. V. Petrochenkova, P. A. Zhikhareva, V. I. Vovna, J. Struct. Chem. $2020,61,1195$.

16. K. A. Romanova, A. Ya. Freidzon, A. A. Bagaturyants, Yu. G. Galyametdinov, J. Phys. Chem. A 2014 , 118,11244 .

17. M. J. Beltrán-Leiva, D. Páez-Hernández, R. Arratia-Pérez, Inorg. Chem. 2018, 57, 5120.

18. J. J. Joos, P. F. Smet, L. Seijo, Z. Barandiarán, Inorg. Chem. Front. 2020 , 7, 871.

19. S. Khan, V. Peters, J. Kowalewski, M. Odelius, Chem. Phys.2018 , $503,56$.

20. D. Azizi, F. Larachi, J. Mol. Liq. 2018 , 263, 96.

21. A. V. Yatsenko, I. P. Gloriozov, N. I. Zhokhova, K. A. Paseshnichenko, L. A. Aslanov, Y. A. Ustynyuk, J. Mol. Liq. 2021 ,323, 115005.

22. N. V. Belova, V. V. Sliznev, D. Christen, J. Mol. Struct.2017, 1132, 34.

23. C. N. M. Ouma, S. Singh, K. O. Obodo, G. O. Amolod, A. H. Romero,Phys. Chem. Chem. Phys. 2017 , 19,25555 .

24. H. Harb, L. M. Thompson, H. P. Hratchian, Phys. Chem. Chem. Phys. 2019, 21, 21890.

25. L. Seijo, Z. Barandiarán, In Handbook on the Physics and Chemistry of Rare Earths; J.-C. G. Bünzli, V. K. Pecharsky, Eds.; Elsevier, Amsterdam, 2016 , Vol. 50, p. 65.

26. Rohini, M. Baral, B. K. Kanungo, J. Coord. Chem. 2019 ,72 , 1497.

27. K. A. Romanova, A. V. Kremleva, Yu. G. Galyametdinov, Int. J. Quantum Chem. 2021, 121, e26569.

28. D. N. Laikov, Chem. Phys. Lett. 1997 , $281,151$.

29. D. N. Laikov, Priroda. Electronic Structure Code. Version 6,2006 .

30. A. A. Knyazev, A. S. Krupin, E. Yu. Molostova, K. A. Romanova, Yu. G. Galyametdinov, Inorg. Chem. 2015, 54, 8987.

31. J. P. Perdew, K. Burke, M. Ernzerhof, Phys. Rev. Lett.1996 , 77, 3865.

32. D. N. Laikov, Chem. Phys. Lett. 2005 , 416 , 116. 
33. T. H. Dunning, J. Chem. Phys. 1989 , 90 , 1007.

34. M. Llunell, D. Casanova, J. Cirera, P. Alemany, S. Alvarez,SHAPE Program for the Stereochemical Analysis of Molecular Fragments by Means of Continuous Shape Measures and Associated Tools , University of Barcelona, Spain, 2013.

35. M. Pinsky and D. Avnir, Inorg. Chem. 1998, $37,5575$.

36. D. Casanova, J. Cirera, M. Llunell, P. Alemany, D. Avnir, S. Alvarez,J. Am. Chem. Soc. 2004 , 126 , 1755 .

37. A. A. Knyazev, Polyfunctional Lanthanide-containing Liquid Crystals: Molecular Structure and Physical-Chemical Properties. Doctoral Dissertation, Kazan National Research Technological University Press, Kazan, 2012 (In Russian).

38. A. A. Granovsky, Firefly. Version 8 , Available at: www http://classic.chem.msu.su/gran/firefly/index.html.

39. M. W. Schmidt, K .K. Baldridge, J. A. Boatz, S. T. Elbert, M. S. Gordon, J. H. Jensen, S. Koseki, N. Matsunaga, K. A. Nguyen, S. Su, T. L. Windus, M. Dupuis, J. A. Montgomery, J. Comput. Chem.1993 , $14,1347$.

40. M. Dolg, H. Stoll, A. Savin, H. Preuss, Theor. Chim. Acta.1989 , $75,173$.

41. M. Dolg, H. Stoll, H. Preuss, Theor. Chim. Acta. $1993,85,441$.

42. S. Grimme, S. Ehrlich, L. Goerigk, J. Comput. Chem.2011, 32, 1456.

43. D. Lapaev, V. Nikiforov, G. Safiullin, V. Lobkov, K. Salikhov, A. Knyazev, Yu. Galyametdinov, Opt. Mater. $2014,37,593$.

44. W. M. Faustino, O. L. Malta, E. E. S. Teotonio, H. F. Brito, A. M. Simas, G. F. J. de Sa, J. Phys. Chem. A $2006,110,2510$.

45. A. N. Carneiro Neto, E. E. S. Teotonio, G. F. de Sá, H. F. Brito, J. Legendziewicz, L. D. Carlos, M. C. F.C. Felinto, P. Gawryszewska, R. T. Moura Jr., R. L. Longo, W. M. Faustino, O. L. Malta, In Handbook on the Physics and Chemistry of Rare Earths; J.-C. G. Bünzli, V. K. Pecharsky, Eds.; Elsevier, Amsterdam, 2019 , Vol. 56, p. 55.

46. F. R. Gonçalves e Silva, R. Longo, O. L. Malta, C. Piguet, J.-C. G. Bünzli, Phys. Chem. Chem. Phys. $2000,2,5400$.

47. K. A. Romanova, N. P. Datskevich, I. V. Taidakov, A. G. Vitukhnovskii, Yu. G. Galyametdinov, Russ. J. Phys. Chem. A $2013,87,2108$.

48. V. A. Blatov, A. P. Shevchenko, D. M. Proserpio, Cryst. Growth Des. 2014, 14, 3576.

49. H. J. Batista, A. V. M. de Andrade, R. L. Longo, A. M. Simas, G. F. de Sa, N. K. Ito, L. C. Thompson, Inorg. Chem. $1998,37,3542$.

50. X.-F. Chen, X.-H. Zhu, Y.-H. Xu, S. S. S. Raj, S. Ozturk, H.-K. Fun, J. Ma, X.-Z. You, J. Mater. Chem. 1999, $9,2919$.

51. M. O. Ahmed, J.-L. Liao, X. Chen, S.-A. Chen, J. H. Kaldis, Acta Cryst. E 2003 , 59 , m29.

52. C. R. Groom, I. J. Bruno, M. P. Lightfoot, S. C. Ward, Acta Cryst. B 2016 , 72, 171.

53. F. T. Silva, S. L. S. Lins, A. M. Simas, Inorg. Chem.2018, 57, 10557.

54. V. R. Sastri, J.-C. G. Bünzli, V. R. Rao, G. V. S. Rayudu, J. R. Perumareddi, In Modern Aspects of Rare Earths and their Complexes; Elsevier Science, Amsterdam, 2003 , p. 375.

55. A. Schoedel, In Metal-Organic Frameworks for Biomedical Applications; M. Mozafari, Eds.; Woodhead Publishing, Cambridge, 2020 , p. 11.

56. A. A. Knyazev, A. S. Krupin, B. Heinrich, B. Donnio, Yu. G. Galyametdinov, Dyes Pigm. 2018 , 148 , 492.

57. K. Binnemans, Yu. G. Galyametdinov, R. Van Deun, D. W. Bruce, S. R. Collinson, A. P. Polishchuk, I. Bikchantaev, W. Haase, A. V. Prosvirin, L. Tinchurina, I. Litvinov, A. Gubajdullin, A. Rakhmatullin, K. Uytterhoeven, L. Van Meervelt, J. Am. Chem. Soc. 2000 , 122, 4335.

58. S. Tobita, M. Arakawa, I. Tanaka, J. Phys. Chem. $1985,89,5649$.

59. G. A. Crosby, R. E. Whan, J. J. Freeman, J. Phys. Chem.1962, 66 , 2493.

60. A. D'Aléo, F. Pointillart, L. Ouahab, C. Andraud, O. Maury, Coord. Chem. Rev. $2012,256,1604$.

61. E. Kasprzycka, V. A. Trush, V. M. Amirkhanov, L. Jerzykiewicz, O. L. Malta, J. Legendziewicz, P. Gawryszewska, Chem. Eur. J.2017, 23, 1318. 
62. Y. H. Zhang, W. Thor, K. L. Wong, P. A. Tanner, J. Phys. Chem. C 2021, 125, 7022.

63. F. Gutierrez, C. Tedeschi, L. Maron, J.-P. Daudey, R. Poteau, J. Azema, P. Tisnès, C. Picard, Dalton Trans. $2004,39,1334$.

64. W. T. Carnall, P. R. Fields, K. Rajnak, J. Chem. Phys.1968 , 49 , 4424.

65. A. Kramida, Yu. Ralchenko, J. Reader, NIST ASD Team (2020), NIST Atomic Spectra Database (ver. 5.8), National Institute of Standards and Technology, Gaithersburg, MD, Available at: https://physics.nist.gov/asd [2022, January 12].

66. M. Latva, H. Takalo, V.-M. Mukkala, C. Matachescu, J. C. Rodriguez-Ubis, J. Kankare, J. Lumin. $1997,75,149$.

67. S. Sato, M. Wada, Bull. Chem. Soc. Jpn. 1970 ,43, 1955.

68. W. R. Dawson, J. L. Kropp, M. W. Windsor, J. Chem. Phys.1966 , 45 , 2410.

69. O. A. Blatova, V. A. Blatov, V. N. Serezhkin, Russ. J. Coord. Chem. 2000 , $26,847$.

70. A. V. Vologzhanina, D. V. Pushkin, V. N. Serezhkin, Acta Cryst. B 2006 , 62 , 754.

71. V. A. Blatov, Crystallogr. Rev. 2004, $10,249$.

72. D. Trzesowska, R. Kruszynski, T. J. Bartczak, Acta Cryst. B2004, 60 , 174.

73. E. V. Peresypkina, V. A. Blatov, Acta Cryst. B $2003,59,361$.

74. V. A. Blatov, V. N. Serezhkin, Yu. A. Buslaev, Russ. J. Inorg. Chem. $2000,45,1707$.

\section{SUPPORTING INFORMATION}

Additional supporting information may be found online in the Supporting Information section at the end of this article.

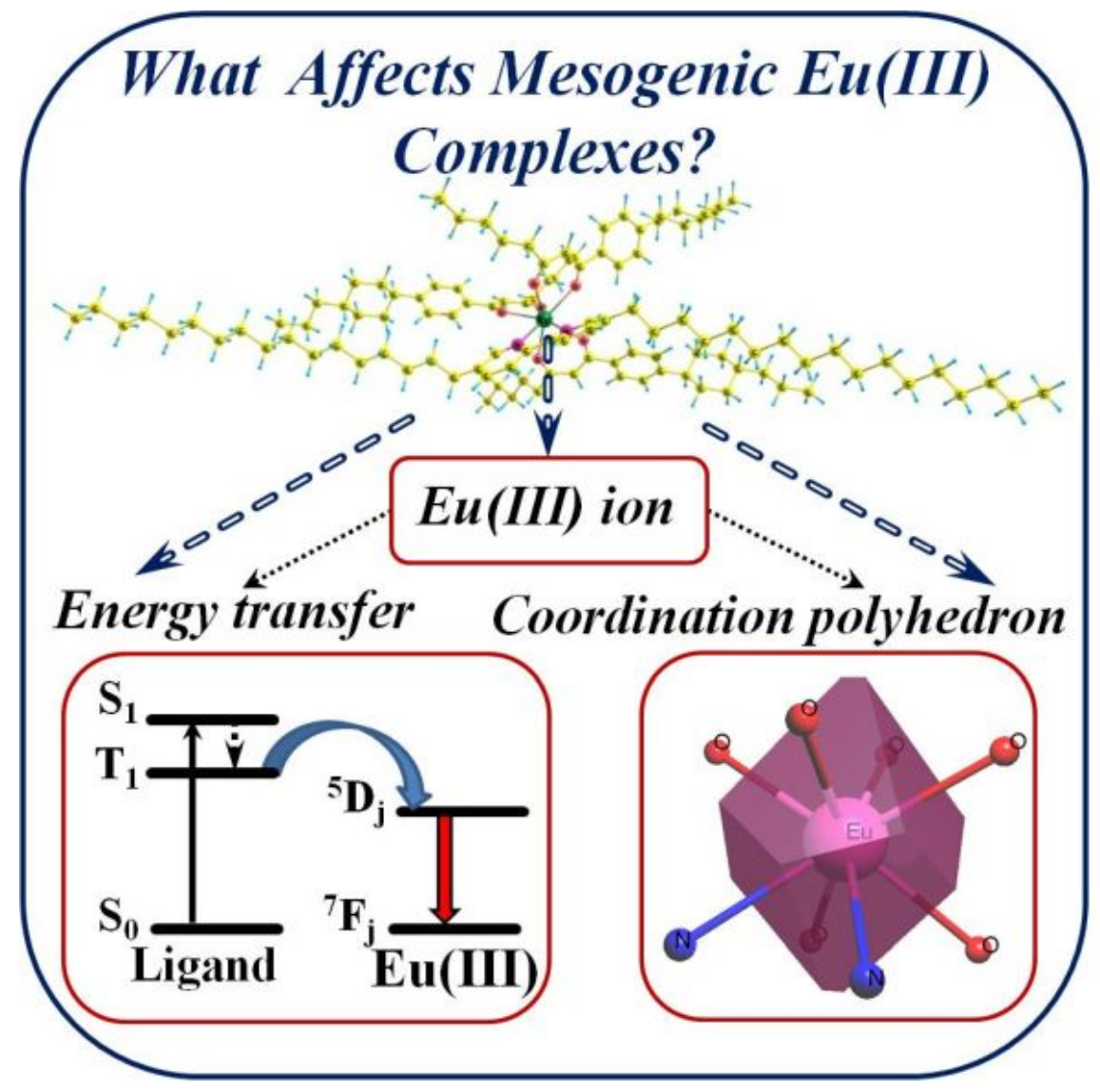



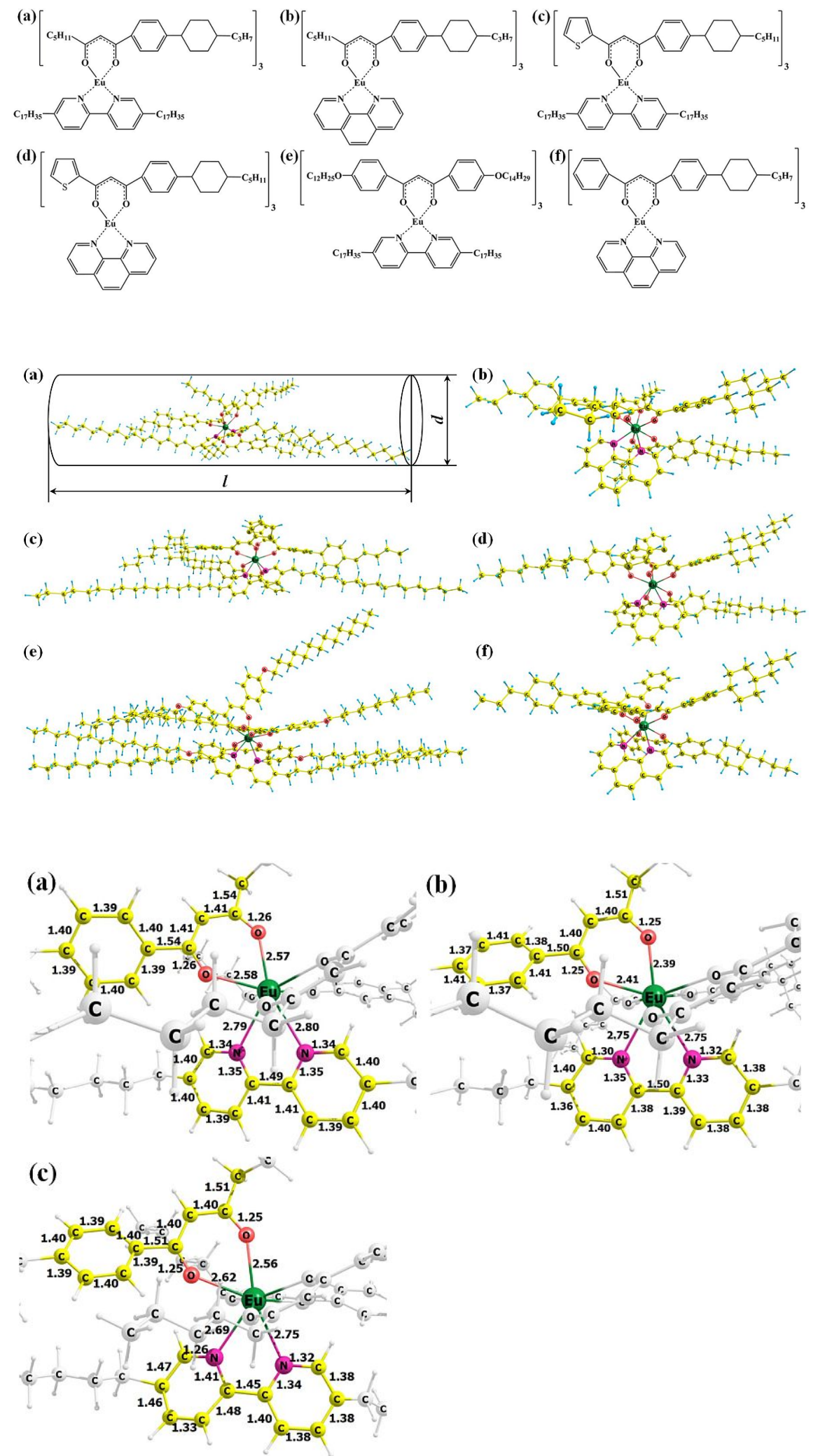

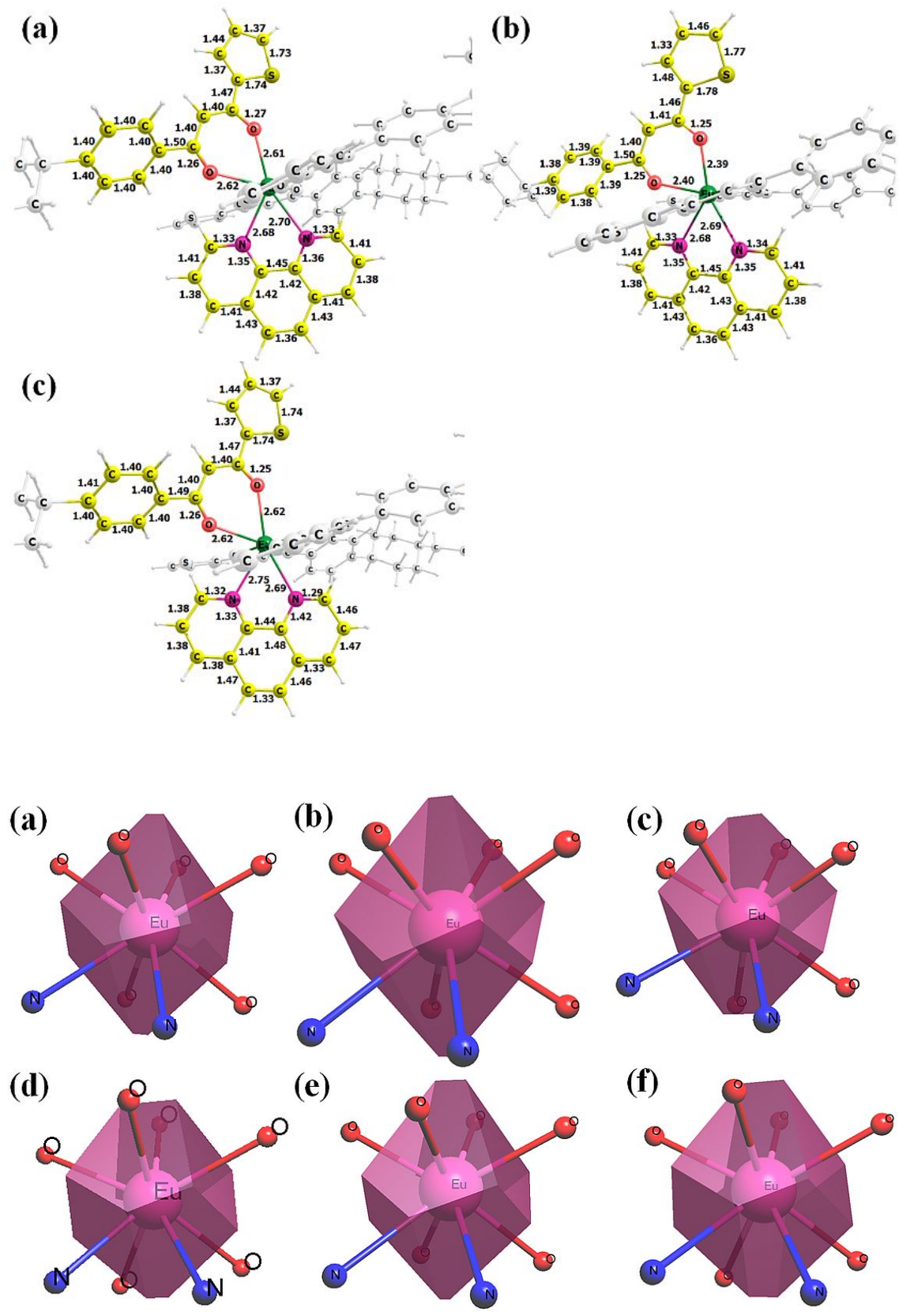

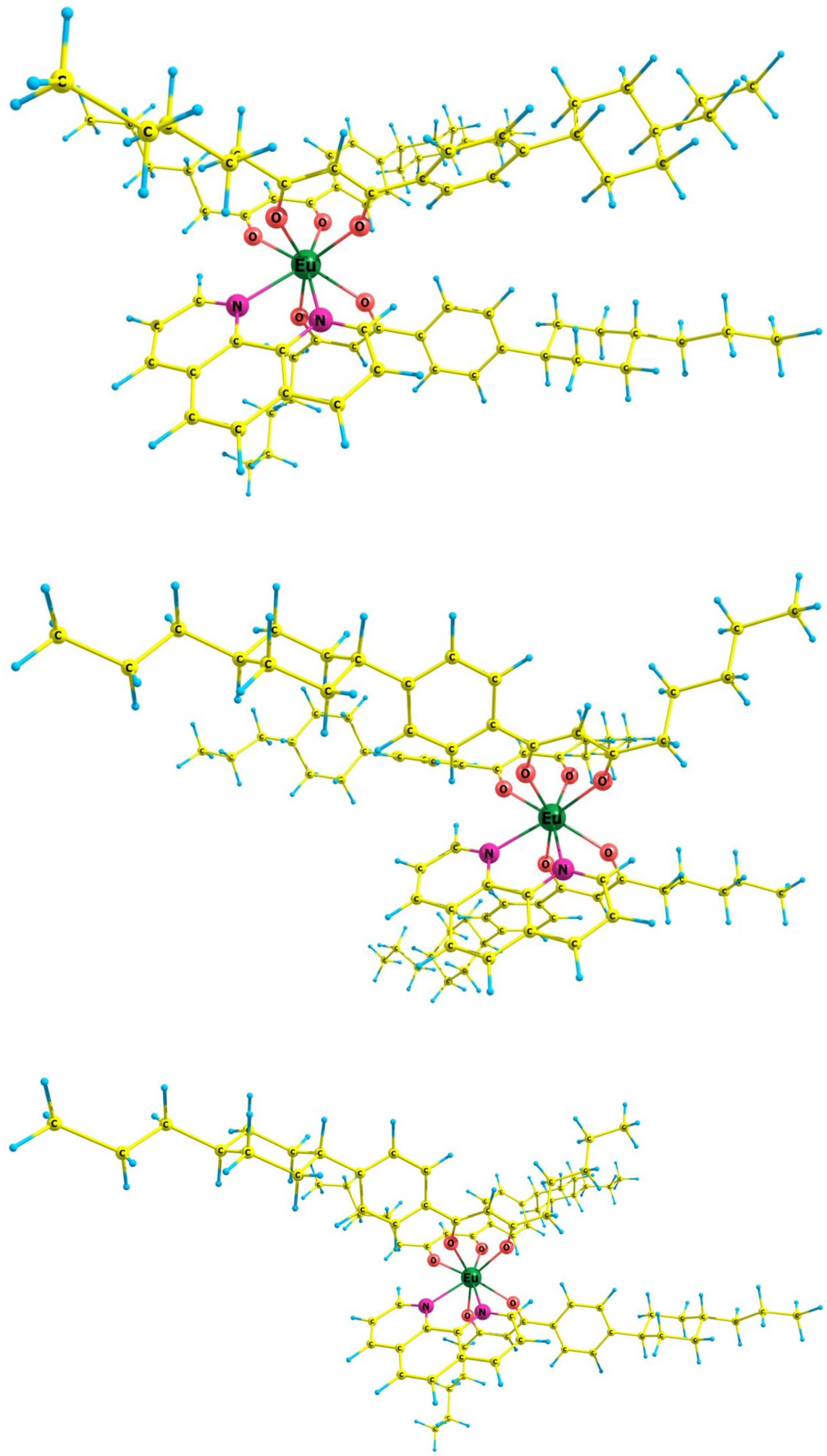

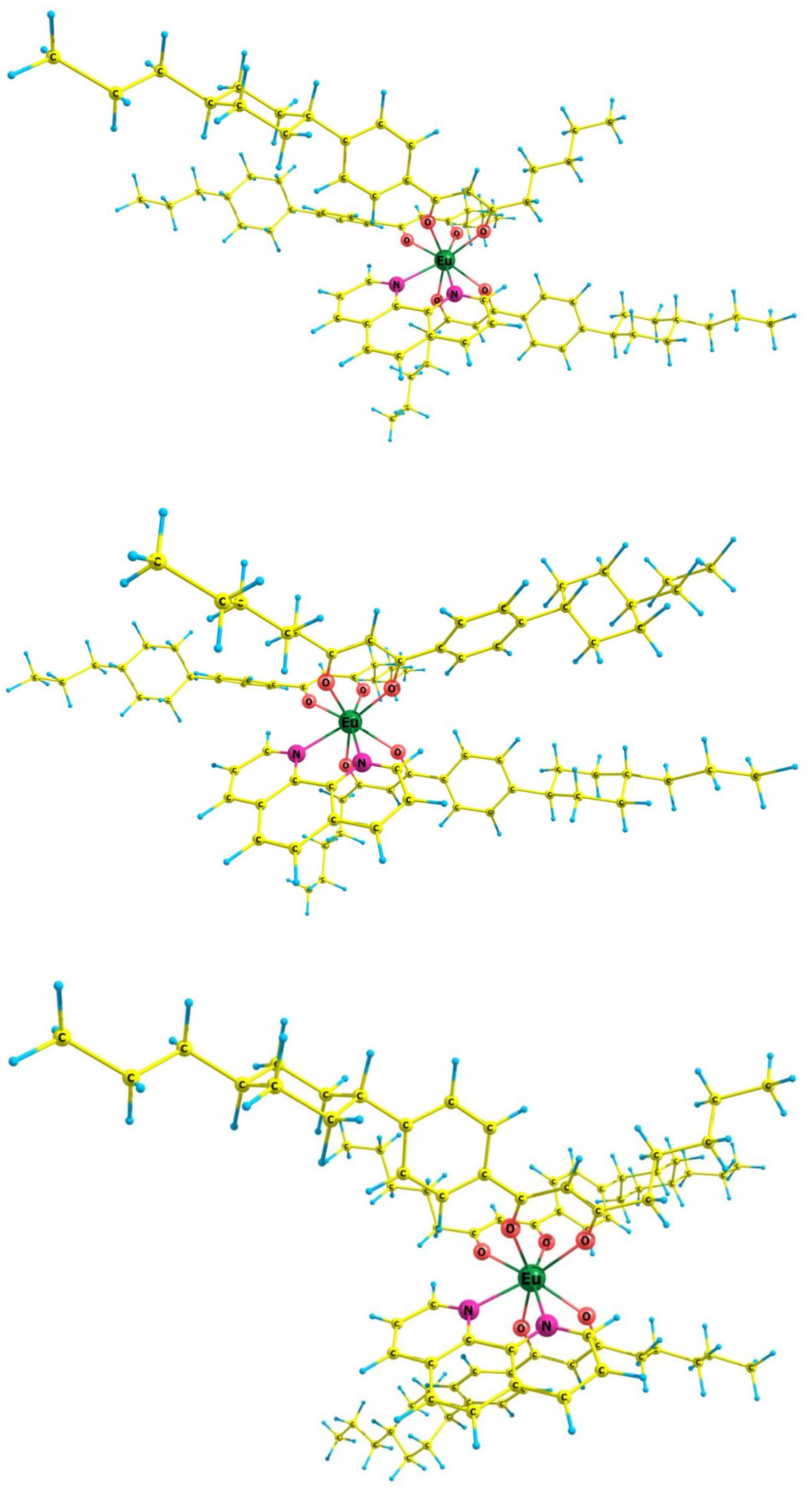

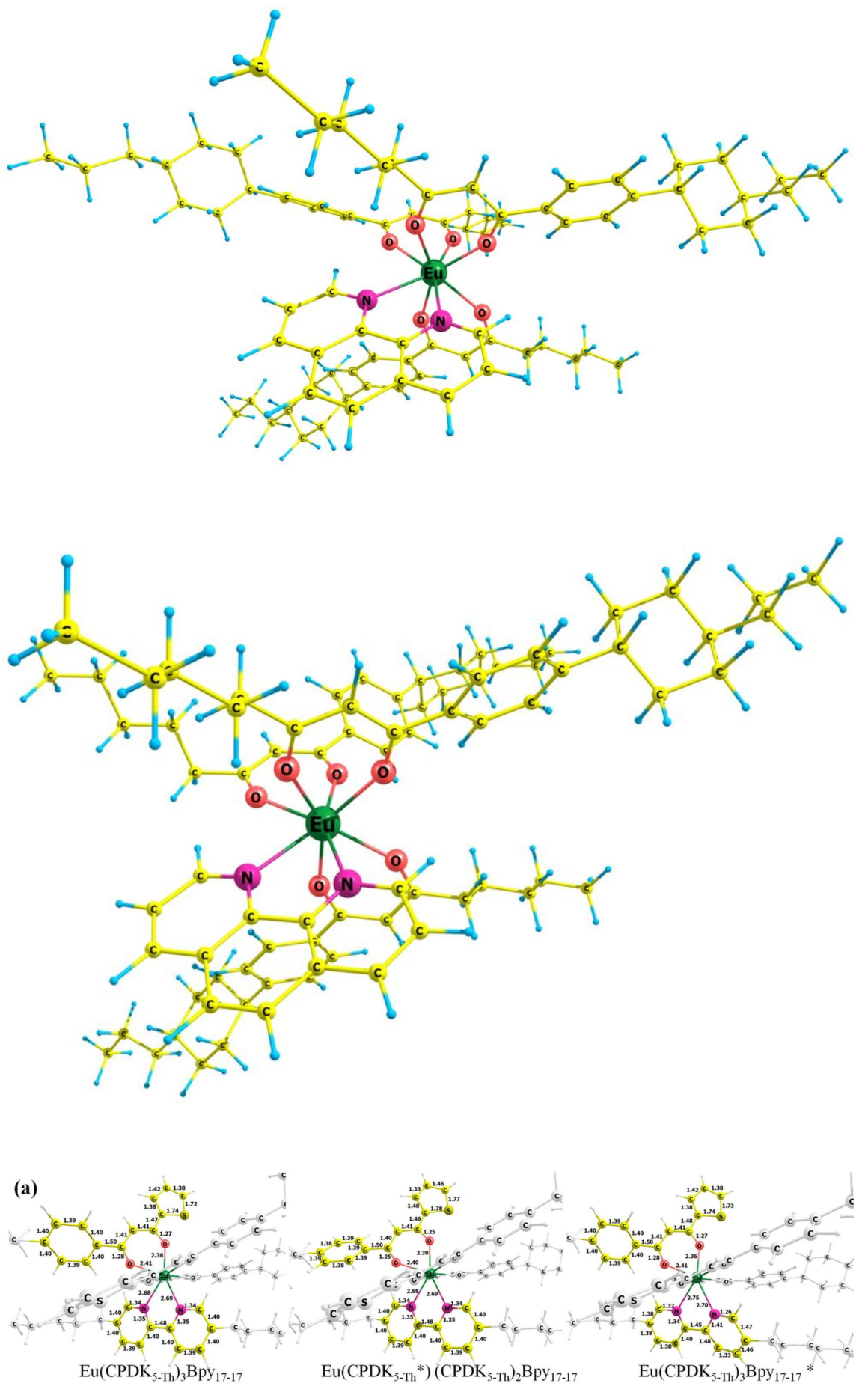


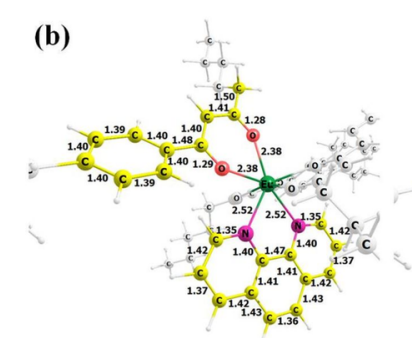

$\mathrm{Eu}\left(\mathrm{CPDK}_{3-5}\right)_{3}$ Phen

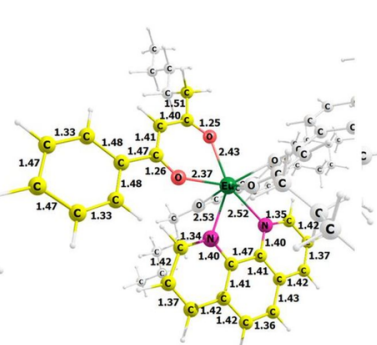

$\mathrm{Eu}\left(\mathrm{CPDK}_{3-5} *\right)\left(\mathrm{CPDK}_{3-5}\right)_{2} \mathrm{Phen}$

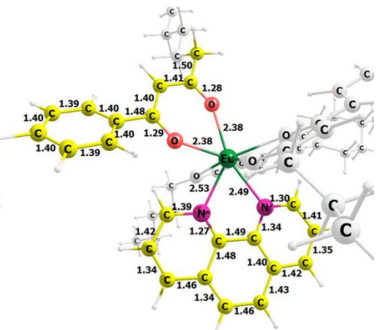

$\mathrm{Eu}\left(\mathrm{CPDK}_{3-5}\right)_{3}$ Phen*

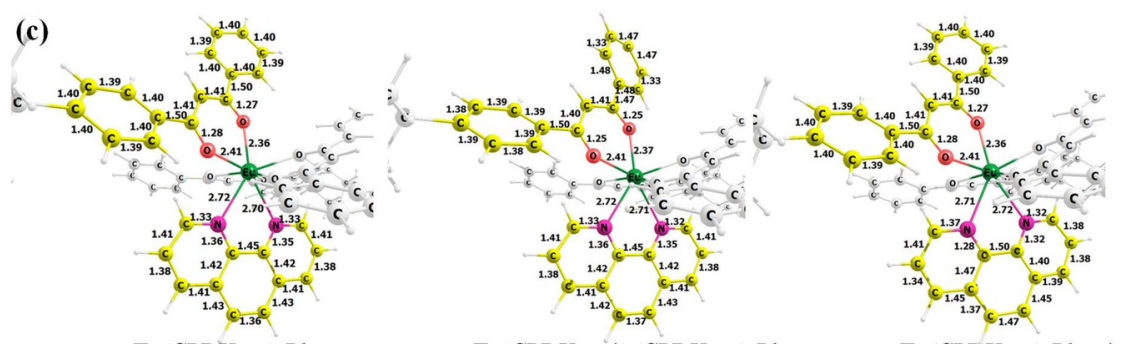

$\mathrm{Eu}\left(\mathrm{CPDK}_{3-\mathrm{Ph}}\right)_{3} \mathrm{Phen}$

$\mathrm{Eu}\left(\mathrm{CPDK}_{3-\mathrm{Ph}}{ }^{*}\right)\left(\mathrm{CPDK}_{3-\mathrm{PH}}\right)_{2}$ Phen

$\mathrm{Eu}\left(\mathrm{CPDK}_{3-\mathrm{Ph}}\right)_{3} \mathrm{Phen}^{*}$

(d)

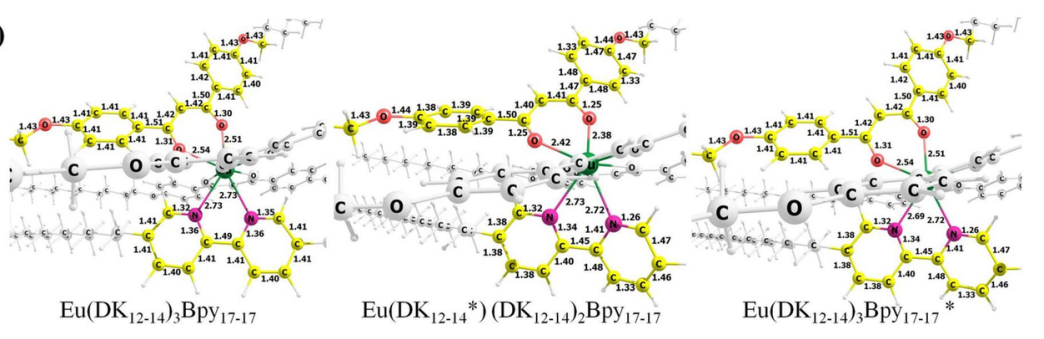

